\title{
Capacidade tecnológica: proposição de índice e aplicação a empresas do complexo agroindustrial do trigo
}

\author{
Claudia De Moria*, Mário Otávio Batalha ${ }^{\mathrm{b}}$, Oscar Alfranca ${ }^{\mathrm{c}}$ \\ a*claudia.de-mori@embrapa.br, Embrapa Trigo, Brasil \\ bdmob@ufscar.br, UFSCar, Brasil \\ coscar.alfranca@upc.edu, UPC, Espanha
}

\begin{abstract}
Resumo
A capacidade tecnológica é um importante fator na determinação da eficiência e da eficácia dos processos produtivos e no grau de inovatividade das empresas. Sua mensuração pode auxiliar as empresas a avaliarem sua capacidade de absorver, usar, adaptar, gerar, desenvolver, transferir e difundir tecnologias. Este trabalho desenvolve um modelo de mensuração de capacidade tecnológica e aplica-o em empresas do complexo agroindustrial tritícola (unidades agrícolas, moinhos e pastifícios). 0 modelo desenvolvido está apoiado no cálculo de cinco macroíndices: (i) recursos; (ii) atualização tecnológica; (iii) processos e rotinas; (iv) mecanismos de aprendizagem; e (v) articulação e acessibilidade. 0 índice consiste em uma somatória ponderada de variáveis quantitativas e qualitativas, utilizando o método de análise multicritério AHP para a definição dos pesos. A análise matriz importância $\mathrm{x}$ desempenho e "gráficos aranha" são utilizados para representar e avaliar os resultados alcançados. 0 modelo proposto foi aplicado a 20 unidades rurais, 5 moinhos e 3 pastifícios.
\end{abstract}

Palavras-chave

Agroindústria. Gestão da tecnologia. Índice de capacidade.

\section{Introdução}

A capacidade tecnológica tem importante papel na obtenção da eficiência do processo produtivo e no grau de inovatividade de uma empresa. Apesar dessa importância inconteste, sua natureza, de caráter difuso e tácito, seus aspectos multidimensionais e sua interdependência do perfil das atividades produtivas impõem dificuldades na identificação de elementos que materializem o conceito e permitam sua mensuração. Em que pesem essas dificuldades, sua mensuração pode auxiliar as empresas a compreenderem seu comportamento e potencial tecnológico, servindo como ferramenta de diagnose e de direcionamento de melhorias.

É dentro desse contexto que este trabalho desenvolve um modelo de mensuração de capacidade tecnológica e aplica-o a empresas do complexo agroindustrial (CAl), especificamente àquelas do setor de derivados de trigo. Esse índice de mensuração pode servir tanto como ferramenta analítica de desempenho para empresas tomadas individualmente como para a avaliação da capacidade tecnológica de setores ou regiões. A construção do modelo foi direcionada para empresas do CAl trigo (unidades agrícolas, moinhos e pastifícios). A escolha desse setor decorre de sua importância econômica, do elevado número de produtos fabricado por esse $\mathrm{CAl}$, da grande heterogeneidade de perfis industriais e ampla distribuição espacial no Brasil. Essas características permitem avaliar a robustez e a capacidade do modelo na captação da diversidade de capacidades tecnológicas de firmas de um dado setor.

Segundo dados da Abia (ASSOCIAÇÃO..., 2012), o setor de derivados de trigo ocupou a sexta colocação no ranking de faturamento dos setores da indústria de alimentos em 2011, com um realizado líquido estimado em R\$21,9 bilhões. Segundo dados do 
censo agropecuário (INSTITUTO..., 2009), o conjunto de produtores de trigo no Brasil é formado por 34,0 mil propriedades, sendo que 52,1\% desses estabelecimentos possuem área total entre $10 \mathrm{e}$ 50 hectares. A estrutura industrial do segmento moageiro brasileiro conta com aproximadamente 220 moinhos, com capacidade de moagem instalada de 15,4 milhões de toneladas (ASSOCIAÇÃO..., 2011). Já o segmento de massas alimentícias é composto por, aproximadamente, 600 indústrias, a maioria de pequeno porte e voltadas para o mercado interno. Segundo a Abima (ASSOCIAÇÃO..., 2012), o Brasil é o terceiro maior produtor mundial de macarrão, após a Itália e os EUA, com capacidade instalada de 1,4 milhão de toneladas, gerando mais de $20 \mathrm{mil}$ empregos diretos.

0 texto está dividido em cinco seções, além desta introdução. A segunda seção contextualiza o complexo agroindustrial tritícola e a terceira apresenta aspectos conceituais de CT, as formas de mensurá-los e aspectos relacionados à construção de índices. A quarta seção apresenta os procedimentos metodológicos empregados e a quinta descreve o modelo proposto e sua aplicação em empresas do segmento. Finalmente, a sexta seção traz as considerações finais.

\section{Referencial teórico}

\subsection{Capacidade tecnológica: alguns aspectos conceituais}

Batalha e Silva (2007) afirmam que a tecnologia desempenha um papel cada vez mais importante como fator explicativo das estruturas industriais e do comportamento competitivo das firmas. Este artigo considera tecnologia em um contexto amplo de conhecimentos, ferramentas, técnicas e sistemas disponíveis para a geração, produção, distribuição e destino final adequado de bens e serviços. A mudança tecnológica na firma pode ser entendida como um processo contínuo de absorção ou geração de conhecimento técnico, ferramentas, técnicas e sistemas que permitam à empresa ofertar produtos e serviços de forma competitiva. Tal fenômeno é condicionado por fatores dos contextos externo e interno que acabam por definir uma dada capacidade tecnológica (CT).

As definições de CT encontradas na literatura demonstram o conteúdo abstrato do conceito e a sua interdependência dos objetivos e do contexto para o qual e no qual é empregado. Algumas definições têm como base elementos estruturais (LEONARDBARTON, 1998; FIGUEIREDO, 2005) e outras, elementos funcionais e estratégicos da empresa (PANDA; RAMANATHAN, 1996; LU; CHEN; WANG, 2007). Em algumas, o foco relaciona-se com o âmbito interno da empresa ou elementos específicos (PACK, 1987; ENOS, 1991; BELL, 1982; NEVES, 2000), em outras, o conceito insere-se num âmbito mais amplo, contemplando aspectos internos e externos (BIGGS; SHAH; SRIVASTAVA, 1995).

Em uma definição mais geral do conceito, que enfoca o processo de aplicabilidade de conhecimentos à atividade econômica, a CT é definida por Marcovitch (1994, p. 175) como o ato de

[...] saber usar o conhecimento disponivel no processo decisório, na produção doméstica, na imitação, na transferência, na difusão ou em qualquer outro mecanismo que traga incremento à produtividade e à qualidade dos produtos.

De um ponto de vista mais específico, algumas definições sugerem que os recursos humanos sejam o locus em que as capacidades tecnológicas estão incorporadas (PACK, 1987; ENOS, 1991), desconsiderando a possibilidade de incorporação da CT nos processos e valores das organizações,

Parte dos autores define CT como esforços internos para assimilar, adaptar e/ou criar tecnologia (LALL, 1982; BELL, 1982). Tais esforços estão ligados aos aprimoramentos em termos de processos e de organização da produção, em produtos, em equipamentos e em projetos técnicos.

Bell e Pavitt (1995) atribuem "natureza difusa” à CT. Segundo os autores, a capacidade tecnológica incorpora os recursos necessários para gerar e gerir mudanças tecnológicas. Tais recursos se acumulam e são incorporados por indivíduos (aptidões, conhecimentos e experiência) e pelos sistemas organizacionais. Guan e Ma (2003) definem CT como um tipo especial de ativo ou recurso que inclue tecnologia, produto, processo, conhecimento, experiência e organização.

Biggs, Shah e Srivastava (1995) ampliam o escopo da definição, incorporando a dimensão de interação empresa-ambiente externo e atribuem importância aos mecanismos de aprendizagem no processo de acumulação. Segundo os autores, além da habilidade de gerar inovações de ponta e a simples soma de educação, treinamento e esforços da empresa para absorver e desenvolver o conhecimento aplicado na produção, a CT compreende o aprendizado dos indivíduos no decurso do trabalho na empresa e a forma com que a empresa reúne e motiva os indivíduos a funcionarem como uma organização e interagirem com seu ambiente externo. Para Serra e Plonski (1997), os principais fatores estimuladores da capacidade tecnológica são os processos de aprendizagem e as estratégias competitivas e tecnológicas. Segundo os autores, a intensidade e a diversidade da utilização 
dos mecanismos de aprendizagem influi fortemente no grau de capacidade tecnológica de uma empresa. Esses autores coadunam-se com trabalhos que relacionam o avanço tecnológico ao estágio do processo de aprendizagem da firma (MALERBA, 1992; LALL, 1992).

Leonard-Barton (1998) sugere que as CTs de uma empresa são compostas por sistemas físicos (equipamentos e instalações), sistemas de gerenciamento, qualificações e conhecimento dos empregados e normas e valores da empresa. Também Figueiredo (2005) menciona que a CT de uma empresa está armazenada em pelo menos quatro componentes: sistemas técnicos físicos, pessoas, sistema organizacional e produtos e serviços.

Algumas definições do conceito abrigam a identificação de tipos de capacidade com base nas dimensões funcional e estratégica da empresa. Panda e Ramanathan (1996) definem capacidades tecnológicas como conjunto de capacidades funcionais (criação/ desenho, produção, marketing e serviços, aquisição e suporte) especificadas segundo o nível de atuação da empresa (estratégico, tático e suplementar).

Neste trabalho, a capacidade tecnológica é definida como a maestria das firmas em absorver, usar, adaptar, gerar, desenvolver, transferir e difundir tecnologias, a qual é materializada pelo conjunto de recursos, de habilidades (operativas, organizacionais e relacionais) e de mecanismos de aprendizagem por elas empregados. Considerando que capacitações constituem construções de segunda ordem, esse conjunto de elementos, que ancora e espelha as capacidades de absorção, de operação e de inovação (adaptação e geração) tecnológica de uma firma, pode ser empregado para a mensuração da CT.

\subsection{Modelos de mensuração de capacidades tecnológicas}

A natureza de caráter tácito da CT impõe dificuldades à identificação dos componentes que integram o conceito e à sua mensuração. Segundo Jonker, Romijn e Szirmai (2006), as tentativas de operacionalizar o conceito na empresa consideram apenas parte do espectro, apresentam problemas de escolha de proxies de mensuração e expõem a complexidade da distinção entre esforços, capacidades e desempenho.

Christensen e Overdorf (2000) sugerem a análise de uma capacitação com base em três dimensões: (a) recursos tangíveis e intangíveis da firma e os processos que os operam; (b) os processos de interação, de coordenação, de comunicação e de tomada de decisão; e (c) a observação dos valores culturais que governam o trabalho cotidiano dos empregados. Malavski, Lima e Costa (2010) sugerem que os conceitos recursos e capacitações podem ser trabalhados na forma de relação de conjuntos hierárquicos, isto é, capacitações constituem construções de segunda ordem, já que a formação de capacitações se dá ao longo do tempo, como fruto da utilização dos recursos e dos processos organizacionais e de gestão responsáveis pela mobilização de recursos. Assim, a capacidade entendida como elemento de mediação condiciona certo grau de indissociabilidade entre ela, os recursos tangíveis e os recursos intangíveis de uma determinada firma, podendo ser os mesmos usados como proxies para a sua análise.

Malavski, Lima e Costa (2010) também sugerem o emprego de uma lógica de progressão de níveis (de básico para avançado) de atributos e de variedade dos elementos considerados pelo aspecto cumulativo das trajetórias tecnológicas. 0 caráter de acumulação e os diferentes graus de complexidade existentes em tecnologias disponíveis permitem pressupor a existência de estágios (níveis) pelos quais a firma transita durante o seu ciclo de vida.

Observam-se, na literatura, trabalhos que se dedicam à proposição de estruturas analíticas de capacidade tecnológica, como os estudos de Katz (1987), Adler e Shenbar (1990), Lall (1992), Panda e Ramanathan (1996), Biggs, Shah e Srivastava (1995), Neves (2000), Miyaji e Soares (2002), Guan e Ma (2003), Yam et al. (2004; 2010), Jonker, Romijn e Szirmai (2006) e Lu, Chen e Wang (2007), sumarizados no Quadro 1.

Com relação ao método, a maioria dos trabalhos disponíveis na literatura apresenta estruturas analíticas gerais, com o uso de indicadores isolados para a realização de análises comparativas descritivas. Alguns trabalhos, como os de Neves (2000), Guan e Ma (2003), Yam et al. (2004, 2010) e Lu, Chen e Wang (2007), avançam no intuito de compor índices agregados de mensuração da CT por meio de somatório ou de médias de escores ou índices ponderados com uso de método Analytical Hierarchy Process (AHP). Observa-se também que a maioria dos trabalhos faz uso de avaliações subjetivas (escala de sete pontos, escore de 1 a 5; baixo - médio - alto etc.) para aferir o estado da empresa com relação a variável/indicador, como no trabalho de Lu, Chen e Wang (2007).

Não existem muitos trabalhos que aplicam o conceito de capacidade tecnológica especificamente a empresas do setor alimentício. Os trabalhos de Neves (2000) e Miyaji e Soares (2002) têm o setor agroindustrial como foco de análise da capacidade tecnológica. No entanto, em ambos, o estudo da CT é realizado pela análise isolada de indicadores (agregação parcial ou estatística descritiva do grupo de empresas analisadas) e uso de análise subjetiva. Já o lpardes (INSTITUTO..., 2005) analisou a ocorrência de gargalos tecnológicos da agroindústria paranaense com base em indicadores agregados de CT. 
Quadro 1. Principais características dos sistemas de mensuração de capacidades tecnológicas.

\begin{tabular}{|c|c|c|}
\hline Autores & Dimensões/variáveis & Método \\
\hline Katz (1987) & $\begin{array}{l}\text { Indicadores de desempenho (p. ex., kg/homem-hora, produção, } \\
\text { matérias-primas/kg de produto), melhoria da qualidade e novos } \\
\text { produtos como indicadores do nível de CT revelado. }\end{array}$ & Proposição de estrutura analítica. \\
\hline $\begin{array}{l}\text { Lall (1992), Figueiredo (2002), } \\
\text { Tacla e Figueiredo (2003), Ariffin e } \\
\text { Figueiredo (2003) }\end{array}$ & $\begin{array}{l}\text { Análise descritiva do processo de acumulação de capacitação } \\
\text { tecnológica das empresas com base em funções (capacidade } \\
\text { de investimento, capacidade de produção e ligações com a } \\
\text { economia) e no grau progressivo das habilidades (níveis básico, } \\
\text { intermediário e avançado). }\end{array}$ & $\begin{array}{l}\text { Análise da evolução da acumulação } \\
\text { e da velocidade das CTs com } \\
\text { base na observação da posição da } \\
\text { empresa com relação aos níveis } \\
\text { de complexidade tecnológica } \\
\text { estabelecidos }\end{array}$ \\
\hline Biggs, Shah e Srivastava (1995) & $\begin{array}{l}\text { Mecanismos de aprendizagem, esforços tecnológicos, } \\
\text { capacidade tecnológica e fator de produtividade total. }\end{array}$ & $\begin{array}{l}\text { Análise isolada de indicadores } \\
\text { estabelecidos para cada categoria. }\end{array}$ \\
\hline Panda e Ramanathan (1996) & $\begin{array}{l}\text { Capacidades estratégicas (capacidades de criação, de desenho } \\
\text { e engenharia e de construção), táticas (capacidades de } \\
\text { produção, de marketing e venda e de serviços), suplementares } \\
\text { (capacidades de aquisição e de suporte) e de direção. }\end{array}$ & $\begin{array}{l}\text { Metodologia de auditoria com base } \\
\text { em matriz de indicadores definidos, } \\
\text { segundo os critérios alto, médio e } \\
\text { baixo. }\end{array}$ \\
\hline Tremblay (1998) & $\begin{array}{l}\text { Motivação e comprometimento para mudar, liderança, } \\
\text { relacionamentos, processo de tomada de decisão, canais } \\
\text { de comunicação, fluxo de informação, interação, tipo de } \\
\text { hierarquia, flexibilidade organizacional e atitude gerencial. }\end{array}$ & $\begin{array}{l}\text { Estudo descritivo comparativo de } \\
\text { casos com base nas variáveis. }\end{array}$ \\
\hline Neves (2000) & $\begin{array}{l}\text { Qualificação de recursos humanos, controle de produção (perfil } \\
\text { do planejamento, engenharia de processos e de produto) e } \\
\text { desenvolvimento de tecnologias. }\end{array}$ & $\begin{array}{l}\text { Índice formado pelo somatório de } \\
\text { escores aferidos pelos entrevistados } \\
\text { de } 1 \text { a } 5 \text { nas variáveis "controle de } \\
\text { produção" e "desenvolvimento de } \\
\text { tecnologias". }\end{array}$ \\
\hline $\begin{array}{l}\text { Guan e Ma (2003), Yam et al. } \\
\text { (2004), Yam et al. (2010), baseados } \\
\text { em Adler e Shenbar (1990) }\end{array}$ & $\begin{array}{l}\text { Capacidade de aprendizagem, de } \mathrm{P} \& \mathrm{D} \text {, de alocação de recursos, } \\
\text { de produção, de marketing, de organização e de planejamento } \\
\text { estratégico. }\end{array}$ & $\begin{array}{l}\text { Critérios avaliados subjetivamente } \\
\text { pelas empresas, usando escala de sete } \\
\text { pontos, e cálculo de média para cada } \\
\text { tipo de capacidade. }\end{array}$ \\
\hline Ipardes (INSTITUTO... 2005) & $\begin{array}{l}\text { Indicadores de esforço de inovação em processo, de esforço } \\
\text { em qualidade, de desempenho em eficiência de processo, de } \\
\text { desempenho em qualidade, de desempenho em inovação de } \\
\text { produto e de articulação local da cadeia produtiva. }\end{array}$ & $\begin{array}{l}\text { Cálculo isolado de cada indicador. } \\
\text { Estrutura de pesos sugerida por } \\
\text { especialistas e normalização pela } \\
\text { distância dos melhores e piores. }\end{array}$ \\
\hline Jonker, Romijn e Szirmai (2006) & $\begin{array}{l}\text { Indicadores de esforço tecnológico (interno formal, interno } \\
\text { informal e de redes) e de capacidade tecnológica (rendimento } \\
\text { do processo, diferenciação horizontal e vertical do produto, } \\
\text { modificações em escala, organização e de insumos). }\end{array}$ & $\begin{array}{l}\text { Estudo descritivo comparativo dos } \\
\text { indicadores. }\end{array}$ \\
\hline Lu, Chen e Wang (2007) & $\begin{array}{l}\text { Capacidade de P\&D, de decisão de inovação (inovatividade de } \\
\text { idéias P\&D, intensidade de colaboração com outros agentes } \\
\text { de P\&D, habilidade de compartilhar conhecimentos, previsão } \\
\text { e avaliação inovações tecnológicas e iniciativas de inovação } \\
\text { do empresário), de marketing (participação no mercado, } \\
\text { competitividade de produtos novos, monitoramento da situação } \\
\text { do mercado, unidade de marketing especializado, exportação), } \\
\text { de manufatura (nível de tecnologia avançada, nível de } \\
\text { qualidade do produto, taxa de sucesso na comercialização, } \\
\text { nível de qualidade do pessoal e tempo do ciclo) e de capital } \\
\text { (habilidade de arrecadação de fundos, alocação ótima, } \\
\text { intensidade de capital de entrada, retorno do investimento). }\end{array}$ & $\begin{array}{l}\text { índice sintético com uso do método } \\
\text { Analytical Hierarchy Process (AHP) } \\
\text { para determinar a ponderação dos } \\
\text { aspectos e da teoria de conjuntos } \\
\text { difusos para realizar o julgamento } \\
\text { subjetivo dos avaliadores. }\end{array}$ \\
\hline
\end{tabular}

Fonte: elaborado a partir da coluna autores, no quadro.

\subsection{Indices}

Índices são normalmente utilizados para mensurar fenômenos. Segundo Lebas (1995, p. 23), mensurar significa

[...] transformar uma realidade complexa em uma sequência de símbolos limitados que podem ser comunicados e reproduzidos sob circunstâncias similares.

A OCDE (ORGANIZAÇÃO..., 2003, p. 5) define índice como um conjunto de parâmetros ou indicadores agrupados. Assim, um índice seria um conjunto de componentes vinculados a um fenômeno e sua agregação compreenderia juízo de valor entre os componentes considerados.

Freudenberg (2003) sugere seguir os seguintes passos na construção de índices: desenvolvimento de uma estrutura teórica para o compósito; identificação e desenvolvimento de variáveis relevantes; normalização das variáveis, para permitir comparações; ponderação de variáveis e do grupo de variáveis; e condução de testes de avaliação.

Com relação à normalização das variáveis, as principais técnicas usadas na literatura são (FREUDENBERG, 2003): desvio padrão da média, distância do líder do grupo, distância da média, 
distância dos melhores e piores resultados e escala categórica.

Uma das dificuldades na construção de um índice reside na forma de agregação dos dados, como ponderar dimensões e aspectos para, ao final, expressar o resultado em índice sem desprezar o processo nem torna-lo subjetivo. Segundo Zambon et al. (2005), é possível agrupar os métodos de definição de pesos em quatro categorias: métodos baseados em ordenação de critérios; em escalas de pontos; em distribuição de pontos; e em comparação de critérios par a par. Dentre os métodos e os procedimentos existentes que empregam comparações pareadas para definição da estrutura de pesos, destaca-se o método de decisão multicritério Analytic Hierarchy Process (AHP).

0 método AHP, originalmente desenvolvido pelo professor Thomas L. Saaty em 1972, para solucionar um problema específico de planejamento, permite obterem-se escalas de razão de comparações pareadas (SAATY, 1991). Resumidamente, o método baseia-se na decomposição e divisão do "problema" usando-se a estruturação hierárquica de critérios/indicadores a partir dos quais se realizam comparações entre pares de critérios/indicadores relativas ao seu grau de importância, estabelecendo matrizes de comparações paritárias. Para as comparações, geralmente se adota uma escala linear de 1 a 9 , a Escala Fundamental de Números Absolutos (SAATY, 2005). Os pesos dos critérios são obtidos valendo-se de uma teoria bem conhecida da álgebra linear. Por meio da técnica do autovetor (vetor de Eigen), o método calcula o peso de cada critério/indicador nos vários níveis hierárquicos, sua taxa e sua razão de consistência. Embora o índice de CT não consista em um problema de decisão, ou seja, não há uma escolha entre empresas, o presente trabalho fará uso do procedimento do método AHP para a definição dos pesos do índice.

0 AHP é o método de auxílio à tomada de decisão por múltiplos critérios (MCDM, do inglês Multiple Criteria Decision Making) mais utilizado em publicações científicas, observando-se que a sua frequência em publicações teve grande crescimento a partir da década de 1990, conforme demonstra estudo bibliométrico sobre tomada de decisão com múltiplos critérios e teoria da utilidade multiatributo conduzido por Wallenius et al. (2008) usando a base de dados ISI no período 1970-2006. Também é um método bastante utilizado no ambiente corporativo, em parte devido à disponibilidade de empresas de consultoria e de softwares que facilitam a sua aplicação (SALOMON, 2010).

Forman e Gass (2001), Guglielmetti, Marins e Salomon (2003), Vilas Boas (2006), Vaidya e Kumar (2006), Ho (2008), Salomon (2010) e lshizaka e Labib (2011) apresentam abrangentes revisões de literatura com aplicação da técnica AHP em processos de tomada de decisão. A literatura é rica em aplicações do AHP em diferentes áreas e focos (engenharia, educação, indústria, setores governamentais, finanças, gestão da produção, marketing, agronegócio, meio ambiente e outros temas), como nos trabalhos de lee (2010), Su, Yu e Zhang (2010), Rosado Júnior, Lobato e Müller (2011), Paoli e Moraes (2011) e Labib (2011).

0 método tem sido alvo de críticas no meio acadêmico. As principais críticas (GOMES, 2007) são: dificuldades na conversão de comparações linguísticas em comparações numéricas; inconsistências impostas pela escala linear de 1 a 9; compreenssão diferenciada das questões entre os participantes que fazem as comparações; inversão na ordem de prioridade das alternativas existentes, com a exclusão ou inclusão de alternativas ou critérios; o número de comparações necessárias pode ser alto; e quanto aos axiomas do método. Boa parte dessas críticas já foram refutadas (GARUTI; SALOMON; SPENCER, 2008; SAATY; VARGAS; WHITAKER, 2009; SALOMON, 2010).

A opção pelo método fundamenta-se por ele permitir o tratamento de múltiplos atributos/ critérios, tanto quantitativos como qualitativos, simultaneamente, ser aplicado em situações que envolvem julgamentos subjetivos, prover medidas de consistência de preferência e apresentar um algoritmo relativamente simples de ser implementado. Para a construção do índice proposto, o método AHP foi empregado, especificamente, para auxiliar no estabelecimento de peso dos critérios que o compõem, facilitando a operacionalização do processo de julgamento e tornando-o mais racional.

\subsection{Matriz importância e desempenho}

Diversos métodos e ferramentas analíticas têm sido empregados para avaliar e direcionar ações de melhoria em bens, serviços e estratégias empresariais. Dentre esses métodos destaca-se a matriz de importância e desempenho desenvolvida por Martilla e James (1977). Trata-se de uma ferramenta gráfica simples, construída com base em julgamentos sobre a importância e o desempenho de cada atributo e que, lastreada por esses julgamentos, recomenda ações de melhoria, manutenção ou desinvestimento. Segundo Azzopardi e Nash (2012), a técnica é uma ferramenta de diagnóstico de decisão que facilita a identificação de prioridades de melhoria, a mobilização de recursos escassos para onde eles são necessários, bem como a harmonização de esforços de planejamento estratégico para aumentar a competitividade relativa.

A interpretação clássica proposta por Martilla e James (1977), com base nas médias das avaliações ou escalas, dividia o espaço bidimensional em quadro quadrantes (importância e desempenho altos, baixa importância e alto desempenho, importância e desempenho baixos e alta importância e baixo 
desempenho), atribuindo ações para cada um desses quadrantes. No entanto, diferentes abordagens têm sido propostas para inferir as zonas de prioridade, tais como os métodos dos dados centrados, escalacentrada e diagonal (AZZOPARDI; NASH, 2012).

Slack (1994) adaptou a matriz importância e desempenho para avaliar o posicionamento da organização comparando-a aos seus principais concorrentes. 0 espaço bidimensional da matriz importância-desempenho (Figura 1) proposta pelo autor é composto por quatro áreas chamadas zonas de excesso (baixa importância e altíssimo desempenho, sendo necessário analisar se recursos em demasia estão sendo utilizados para atingir esse nível), adequada (importância e desempenho equilibrados no curto e médio prazo, porém no longo prazo os concorrentes desejarão se mover para o limite superior), de melhoramento (fator importante e desempenho intermediário entre a zona de equilíbrio e de baixíssimo desempenho) e de ação urgente (fatores de alta importância e baixo desempenho da empresa, críticos) (SLACK; LEWIS, 2009).

Como será visto mais à frente, este artigo utilizará a ideia da matriz importância-desempenho para propor uma matriz analítica voltada às especificidades da problemática abordada neste texto.

\section{Procedimentos metodológicos}

A pesquisa utilizou a modelagem como método, a pesquisa bibliográfica e a pesquisa de observação (entrevistas com especialistas) na definição dos elementos do índice e, posteriormente, pesquisas de observação (entrevistas com propriedades rurais e empresas) para análise da aplicabilidade do modelo proposto. Dado que o objetivo da pesquisa consiste no desenvolvimento de instrumental referencial (indice) para mensuração, este trabalho tem caráter de pesquisa aplicada.

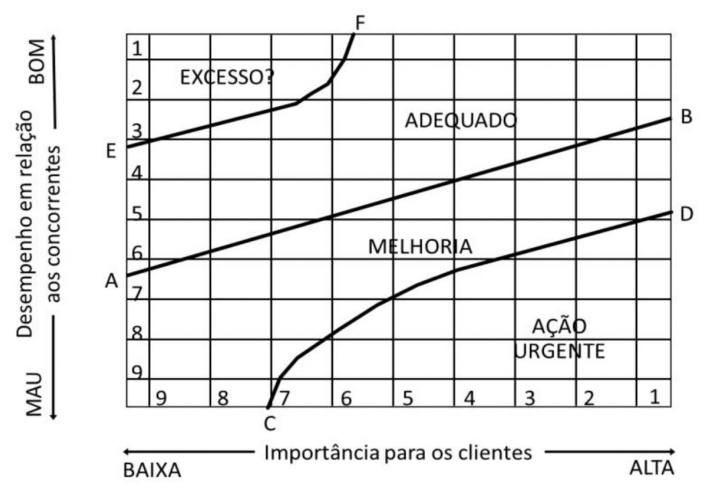

Figura 1. Matriz importância-desempenho. Fonte: adaptado de Slack e Lewis (2009).
As etapas para o desenvolvimento e aplicação do índice foram:

a) Estabelecimento de um quadro de referência e da estrutura arborescente de mensuração da CT com base na revisão de literatura e em pesquisa realizada com 16 especialistas das áreas de produção agrícola e processamento industrial de derivados de trigo;

b) Definição da normalização a ser utilizada, estabelecimento da estrutura dos pesos (com base no método AHP) e elaboração de estrutura de cálculo;

c) Elaboração de instrumento de coleta de dados (questionário) e aplicação por meio de entrevistas para coleta de dados em unidades agrícolas e empresas agroindustriais selecionadas; e

d) Cálculo do índice para os casos entrevistados, construção de gráficos e análise de resultados.

A definição da arquitetura do modelo teve como base a revisão de literatura, por meio da qual se elaborou um conjunto preliminar de elementos relacionados ao conteúdo do conceito e utilizados nas estruturas analíticas de mensuração da capacidade tecnológica encontradas na literatura. Entrevistas de profissionais atuantes no segmento foco (produção de grãos de trigo e derivados) foram realizadas para identificar os principais elementos diferenciadores da capacidade tecnológica das empresas, a pertinência das dimensões contempladas e, especialmente, construir a árvore de variáveis e suas escalas/categoria. Foram entrevistados dez profissionais vinculados à produção primária com atuação nas áreas de melhoramento genético, manejo e conservação de solo, manejo de cultura, nutrição de plantas, mecanização agrícola, fitopatologia, entomologia e entomologia de pós-colheita de três instituições (Universidade Federal do Rio Grande do Sul, Embrapa Trigo e Fundação Meridional) e seis profissionais relacionados ao segmento industrial das áreas de tecnologia de alimentos, qualidade tecnológica/cereais de inverno, tecnologia de alimentos/moagem e derivados de trigo/ massas de cinco instituições (Embrapa Agroindústria, Embrapa Trigo, Universidade Estadual de Londrina, Universidade de Campinas e Bülher).

0 cálculo do índice envolve a caracterização de um valor unidimensional a partir da agregação de variáveis normalizadas com base em um conjunto de pesos (Equação 1). A determinação do conjunto de pesos que compõem o índice foi efetuada com base no método Analytical Hierarchy Process (AHP). Procedimento análogo foi realizado por $\mathrm{Lu}$, Chen e Wang (2007).

$I C T=\sum_{i=1}^{x} w_{i} \bar{X}_{i}$

onde,

ICT: Índice de Capacidade Tecnológica;

$\bar{X}_{i}$ : variável normalizada; e

$\mathrm{w}_{\mathrm{i}}$ : pesos de $\bar{X}_{i}, \sum_{i=1}^{x} w_{i}=1 \mathrm{e} 0 \leq \mathrm{w}_{\mathrm{i}} \leq 1 \quad i: 1, \ldots, n$. 
0 conjunto de pesos foi estabelecido de acordo com as seguintes etapas:

a) Julgamentos paritários. Com base na arquitetura do índice, formulada na etapa anterior, foram construídas matrizes de comparação par a par para o conjunto de elementos. Tendo como base o pressuposto de especificidade de cada segmento em função da natureza da atividade produtiva e tecnológica, o estabelecimento do conjunto de pesos foi realizado para cada um dos segmentos foco (trigo grão, moagem e massas), ou seja, para cada segmento foram preenchidas matrizes de julgamento específicas. Numa primeira etapa, o preenchimento das matrizes de julgamento foi realizado por quatro profissionais (dois vinculados às áreas de manejo de culturas de inverno - matrizes do segmento produção trigo grão - e dois vinculado à qualidade tecnológica/cereais de inverno - matrizes dos segmentos moagem e massas), segundo a escala de valoração do Quadro 2. Pautados nas similaridades e médias entre os julgamentos desses profissionais, os pesquisadores construíram matrizes sintéticas de julgamento que definiram o conjunto de pesos.

b) Cálculo das prioridades locais e globais. Construção do conjunto de pesos por meio do cálculo do vetor Eigen principal (Equação 2) e do máximo vetor de Eigen (Equação 3).

$w_{i}=\left[\prod_{j=1}^{n} a_{i j}\right]^{1 / n} / \sum_{k=1}^{n}\left[\left(\prod_{j=1}^{n} a_{k j}\right)^{1 / n}\right]$

onde,

$a_{i j}$ : valor da matriz par a par correspondente à comparação entre o indicador $i$ e indicador $j$;

$n$ : número de indicadores; $\mathrm{e}$

$w_{i}$ : peso do indicador $i$.

$\lambda_{\max }=\frac{1}{n}\left(\sum_{i=1}^{n} \frac{w_{n}^{\prime}}{w_{n}}\right)$ onde,

$w_{n}^{\prime}$ : valor resultante da multiplicação da matriz A de comparação par a par e o vetor obtido na etapa anterior.

c) Cálculo do grau de consistência (CR). 0 grau de consistência é obtido pela razão entre o índice de consistência (Cl) (Equação 4) e o índice de aleatoriedade (RI). Saaty (1991) propõe valores de $\mathrm{Rl}$ através do cálculo do valor médio de $\mathrm{Cl}$ obtido por matrizes recíprocas geradas aleatoriamente, assim, os valores de Rl, de acordo com o número de indicadores em análise, são os apresentados no Tabela 1. Caso o grau de consistência (CR) seja superior a 0,1 ou $10 \%$, é necessário fazer uma reavaliação da matriz de comparação, ou seja, reavaliar os valores definidos na matriz propondo uma nova matriz de comparação par a par. Para os casos em que o valor do CR foi superior a 10\%, os pesquisadores realizaram a reavaliação das matrizes de julgamento. No entanto, esse procedimento restringiu-se a quatro ocorrências.

$C I=\frac{\lambda_{\max }-n}{n-1}$

onde,

$\lambda_{\max }:$ valor máximo do vetor Eigen;

$n:$ número de indicadores.

Para a normalização das variáveis, empregou-se a distância do líder do grupo (FREUDENBERG, 2003) para cada variável, em que se designa valor 1 ao maior valor observado (líder) e ordenam-se os demais em relação ao valor do líder (Equação 5).

$\bar{X}_{i}=\frac{x_{i}}{x_{i}^{*}}$

onde,

$\bar{X}_{i}$ : variável normalizada;

$x_{i}$ : valor da variável; e

$x_{i}^{*}$ : valor máximo observado da variável.

Quadro 2. Escala de comparação para preenchimento das matrizes de julgamento AHP.

\begin{tabular}{|c|c|c|c|c|c|c|c|c|}
\hline $1 / 9$ & $1 / 7$ & $1 / 5$ & $1 / 3$ & 1 & 3 & 5 & 7 & 9 \\
\hline extremamente & bastante & muito & pouco & igual & pouco & muito & bastante & extremamente \\
\hline & & & & & & & & \\
\hline
\end{tabular}

Fonte: adaptado de Saaty (1991).

Tabela 1. Índice de aleatoriedade (RI) para $\mathrm{n}=1 \ldots 15$.

\begin{tabular}{cccccccccc}
\hline$N$ & $\mathrm{Rl}$ & $N$ & $\mathrm{Rl}$ & $n$ & $\mathrm{Rl}$ & $n$ & $\mathrm{Rl}$ & $n$ & $\mathrm{Rl}$ \\
\hline 1 & 0,00 & 4 & 0,09 & 7 & 1,32 & 10 & 1,49 & 13 & 1,56 \\
2 & 0,00 & 5 & 1,12 & 8 & 1,41 & 11 & 1,51 & 14 & 1,57 \\
3 & 0,58 & 6 & 1,24 & 9 & 1,45 & 12 & 1,48 & 15 & 1,59 \\
\hline
\end{tabular}

Fonte: adaptado de Saaty (1991). 
No caso de variáveis qualitativas ordinais, optou-se por considerar o descritor de maior nível como valor 1 (líder), independente de não haver registro do nível no grupo entrevistado.

A partir da estrutura arborescente foi elaborado um questionário para cada segmento estudado. Para aplicação no segmento agrícola, selecionaram-se duas importantes regiões produtoras nos dois principais estados produtores de trigo e contou-se com o auxílio da Emater/PR e Emater/RS para a coleta de dados. No caso das unidades agroindustriais, partiu-se de uma listagem de moinhos e pastifícios e selecionaram-se empresas com diferentes idades e tamanhos. As entrevistas foram realizadas com gerentes (geral, técnico, industrial ou de produção), técnicos responsáveis e/ou proprietários. Os dados coletados sofreram um processo de sistematização e tabulação. Foi realizado o cálculo do índice para cada unidade/empresa e das médias para o conjunto de unidades por segmento

0 cálculo dos índices foi realizado em planilha eletrônica de dados Excel ${ }^{\circledR}$. Para auxiliar a análise de ações futuras por parte das empresas foi empregada, com adaptações para as características do estudo, a matriz de importância $x$ desempenho apresentada por Slack (1994). Essa matriz permite avaliar o posicionamento da organização frente aos concorrentes, indicando possíveis ações de melhoria, manutenção ou desinvestimento. A construção de "gráficos aranha" das variáveis do modelo foi realizada como mecanismo de complementação à análise dos resultados.

\section{Apresentação do modelo e resultados}

Esta seção apresenta o modelo proposto e sua aplicação ao complexo agroindustrial do trigo.

\subsection{Modelo proposto}

Com base nas definições de capacidade tecnológica e nos trabalhos de mensuração disponíveis na literatura, a construção do modelo pautou-se pelos seguintes referenciais:

a) 0 desenvolvimento tecnológico de uma empresa reúne uma multiplicidade de elementos que conferem ao tema mais complexidade do que a análise de alguns pontos isolados (BELL; PAVITT, 1993; BIGGS; SHAH; SRIVASTAVA, 1995; LEONARD-BARTON, 1998; FIGUEIREDO, 2005; JONKER; ROMIJN; SZIRMAI, 2006). A capacidade tecnológica está espelhada nas dimensões de operacionalização, organização (STALK; EVANS; SHULMAN, 1992; LALL, 1992; CHRISTENSEN; OVERDORF, 2000) e relacional de uma firma (LALL, 1992). Considerando sua natureza difusa, as CTs estão imbuídas nas diversas estruturas e funções da empresa, nas operações básicas de manufatura, no controle de qualidade, nos mecanismos de treinamento, na P\&D formal, na qualificação de recursos humanos e assim por diante. Nesse sentido, o conteúdo tecnológico de uma empresa está imbricado em (i) um conjunto de recursos e tecnologias operativas de manufatura associados a diferentes funções executadas pela empresa, (ii) um conjunto de processos organizacionais que contribuem para seu desenvolvimento tecnológico e (iii) na interação que a empresa possui com o ambiente em que está inserida;

b) A CT pode ser compreendida como específica para cada atividade produtiva (LU; CHEN; WANG, 2007). Em atividades da indústria de alimentos, componentes associados à manufatura propriamente dita são muito importantes. Portanto, um índice de capacidade tecnológica deve considerar fatores particulares ao setor analisado e um conjunto de pesos também específicos para esse setor;

c) Considerando que capacitações constituem elementos de seleção, de interação e de coordenação entre inputs e processos na produção de bens e de serviços, o conceito de capacitação pode ser considerado uma construção de segunda ordem, operacionalizada na forma de relações de conjuntos hierárquicos e com uma lógica de progressão de níveis, do básico para o avançado (MALAVSKI; LIMA; COSTA, 2010). Considerando-se certo grau de indissociabilidade entre recursos tangiveis, recursos intangiveis e capacidades de uma determinada firma, os recursos propriamente ditos podem ser usados como proxies para análise de uma dada CT. Parte-se do pressuposto de que a expressão do grau de capacidade tecnológica de uma determinada empresa pode ser vislumbrada através de elementos como o grau de instrução dos empregados, o uso de uma tecnologia avançada disponível no mercado ou, por exemplo, o grau de interação com demais agentes produtivos, dentre outros elementos;

d) 0 caráter de acumulação permite pressupor a existência de estágios (de nível básico a avançado) pelos quais a firma transita durante o seu ciclo de vida, em especial na absorção das tecnologias de manufatura disponíveis no mercado.

0 Quadro 3 apresenta o comparativo de referências teóricas do modelo de mensuração com base na avaliação da literatura e nas entrevistas realizadas. Seus componentes espelham a CT de uma empresa, a inserção desses componentes nas dimensões da firma (operacional, organizacional e relacional), bem como descrevem, sucintamente, a relevância e os autores que apontam tais componentes como relacionados à CT. Esse quadro deu origem à estrutura arborescente que compõe o índice de mensuração da CT proposto neste trabalho. 
Quadro 3. Elementos de mensuração de capacidade tecnológica, sua inserção nas dimensões da firma, sua relevância e autores de referência.

\begin{tabular}{|c|c|c|c|}
\hline $\begin{array}{c}\text { DIMENSÃO DA } \\
\text { FIRMA }\end{array}$ & COMPONENTE & RELEVÂNCIA & BIBLIOGRAFIA \\
\hline \multirow[t]{2}{*}{ OPERACIONAL } & Recursos & $\begin{array}{l}\text { Abrange o perfil de intensidade de investimentos, de } \\
\text { recursos humanos e da infraestrutura da empresa. Reflete o } \\
\text { comprometimento e o estoque de recursos da empresa para } \\
\text { dar suporte ao processso produtivo e às mudanças técnicas. }\end{array}$ & $\begin{array}{l}\text { OCDE (ORGANIZAÇÃO..., 2005), } \\
\text { Coombs e Bierly (2006), IBGE } \\
\text { (INSTITUTO..., 2007), Pack (1987), } \\
\text { Enos (1991), Bell e Pavitt (1995), } \\
\text { Biggs, Shah e Srivastava (1995), } \\
\text { Leonard-Barton (1998), Neves } \\
\text { (2000), Christensen e Overdorf } \\
\text { (2000) e Figueiredo (2005) }\end{array}$ \\
\hline & $\begin{array}{l}\text { Atualização } \\
\text { tecnológica }\end{array}$ & $\begin{array}{l}\text { Evidencia o perfil de uso de tecnologia nas diferentes } \\
\text { etapas do processso de manufatura/produção. Revela a } \\
\text { experiência acumulada e distingue o nivel de complexidade } \\
\text { do conteúdo tecnológico empregado pela empresa, bem } \\
\text { como sua potencialidade de utilizar e controlar tecnologias. }\end{array}$ & $\begin{array}{l}\text { Severiano Filho (1995), Leonard- } \\
\text { Barton (1998) e Lu, Chen e Wang } \\
\text { (2007) }\end{array}$ \\
\hline \multirow[t]{2}{*}{ ORGANIZA-CIONAL } & Processos e rotinas & $\begin{array}{l}\text { Relaciona-se a ações gerenciais correlacionadas ao } \\
\text { conteúdo tecnológico. Exprime a capacidade de estabelecer } \\
\text { as ações, planejar, monitorar e controlar o conteúdo } \\
\text { tecnológico e os projetos a serem desenvolvidos pela } \\
\text { empresa, a capacidade de gerenciar e de realizar melhorias } \\
\text { (adaptar, reparar, replicar ou criar) em seus produtos e em } \\
\text { seus processos, bem como de integrar seus recursos. }\end{array}$ & $\begin{array}{l}\text { Clark e Fujimoto (1991), Lall } \\
\text { (1992), Bell e Pavitt (1993), } \\
\text { Dichter et al. (1998), Leonard- } \\
\text { Barton (1998), Christensen e } \\
\text { Overdorf (2000) e Neves (2000) }\end{array}$ \\
\hline & $\begin{array}{l}\text { Mecanismos de } \\
\text { aprendizagem }\end{array}$ & $\begin{array}{l}\text { Abrange os mecanismos de aquisição, socialização e } \\
\text { codificação de conhecimentos. Revela o fluxo de ações } \\
\text { desenvolvidas pela empresa para gerar conhecimentos e } \\
\text { incorporá-los ao seu capital. }\end{array}$ & $\begin{array}{l}\text { Malerba (1992), Lall (1992), Garvin } \\
\text { (1993), Biggs, Shah e Srivastava } \\
\text { (1995), Leonard-Barton (1998), } \\
\text { Figueiredo (2002), Castro (2002) e } \\
\text { Tacla e Figueiredo (2003) }\end{array}$ \\
\hline RELACIONAL & $\begin{array}{l}\text { Articulação e } \\
\text { acessibilidade }\end{array}$ & $\begin{array}{l}\text { Explora o desenvolvimento da capacidade de receber } \\
\text { informações, habilidades e tecnologias, considerando- } \\
\text { se a amplitude das ligações com o ambiente externo e } \\
\text { a intensidade de relacionamento. Focaliza aspectos de } \\
\text { relacionamentos com fornecedores, acesso a informação } \\
\text { tecnológica, intensidade de participação em eventos etc. }\end{array}$ & $\begin{array}{l}\text { Lall (1992), Biggs, Shah e Srivastava } \\
\text { (1995) e OCDE (ORGANIZAÇÃO..., } \\
\text { 2005) }\end{array}$ \\
\hline
\end{tabular}

Nesse sentido, o Índice de Capacidade Tecnológica (ICT) proposto é composto por multiatributos em arquitetura arborescente (Figura 2). Ele deriva do desdobramento dos cinco componentes descritos no Quadro 3 e que resultaram em três níveis hierárquicos (macroíndice, mesoíndice e indicador).

0 modelo de ICT é formado por cinco macroíndices:

(i) Recursos (RE), composto pelos mesoíndices Intensidade de investimento (1I), Recursos humanos (RH) e Infraestrutura (IE);

(ii) Atualização tecnológica (AT), formado por mesoíndices, compostos segundo as etapas de processamento: Pré-processamento (PP), Processamento (P), Controles (CT) e Estocagem, empacotamento e distribuição (EE);

(iii) Processos e rotinas (PR), integrado pelos mesoíndices Planejamento e controle (PC), Monitoramento e gestão de projeto (MG), Engenharia de produto (EP) e Engenharia de processo (EPC);

(iv) Mecanismos de aprendizagem (MA), desagregado nos indicadores Mecanismos internos (MI), Mecanismos externos (ME), Socialização (S) e Codificação (C); e

(v) Articulação e acessibilidade (AA), composto pelos indicadores Interação com o ambiente externo (IA), Articulação com fornecedores (AF), Fontes de informação tecnológica acessadas (FI) e pelo mesoíndice Intensidade de participação em eventos (IP).

Com o intuito de contemplar as especificidades da CT para cada segmento foco (produção primária de trigo, moagem e massas), a arquitetura mestre proposta é particularizada, ou seja, a arquitetura do indice contempla um conjunto de indicadores gerais para todas as organizações e um conjunto específico ou simplificado por segmento. Por exemplo, a Intensidade de investimento (mesoíndice) é mensurada no segmento industrial buscando identificar a diversidade e o percentual de gasto da empresa em atividades inovativas segundo a OCDE (ORGANIZAÇÃO...,2005) (atividades internas de $\mathrm{P} \& \mathrm{D}$, aquisição externa de $P \& D$, aquisição de outros conhecimentos externos, aquisição de software, aquisição de máquinas e equipamentos, treinamento, lançamento de produtos ou processos novos e projeto industrial e outras preparações técnicas). No entanto, esse conjunto de indicadores não faz sentido em uma propriedade rural, sendo a Intensidade de investimento mensurada pelo gasto global em atividades inovativas no caso das unidades agrícolas. De forma semelhante e já mencionada nos procedimentos metodológicos, para cada segmento foi elaborado um conjunto de pesos. A apresentação pormenorizada do índice para cada 


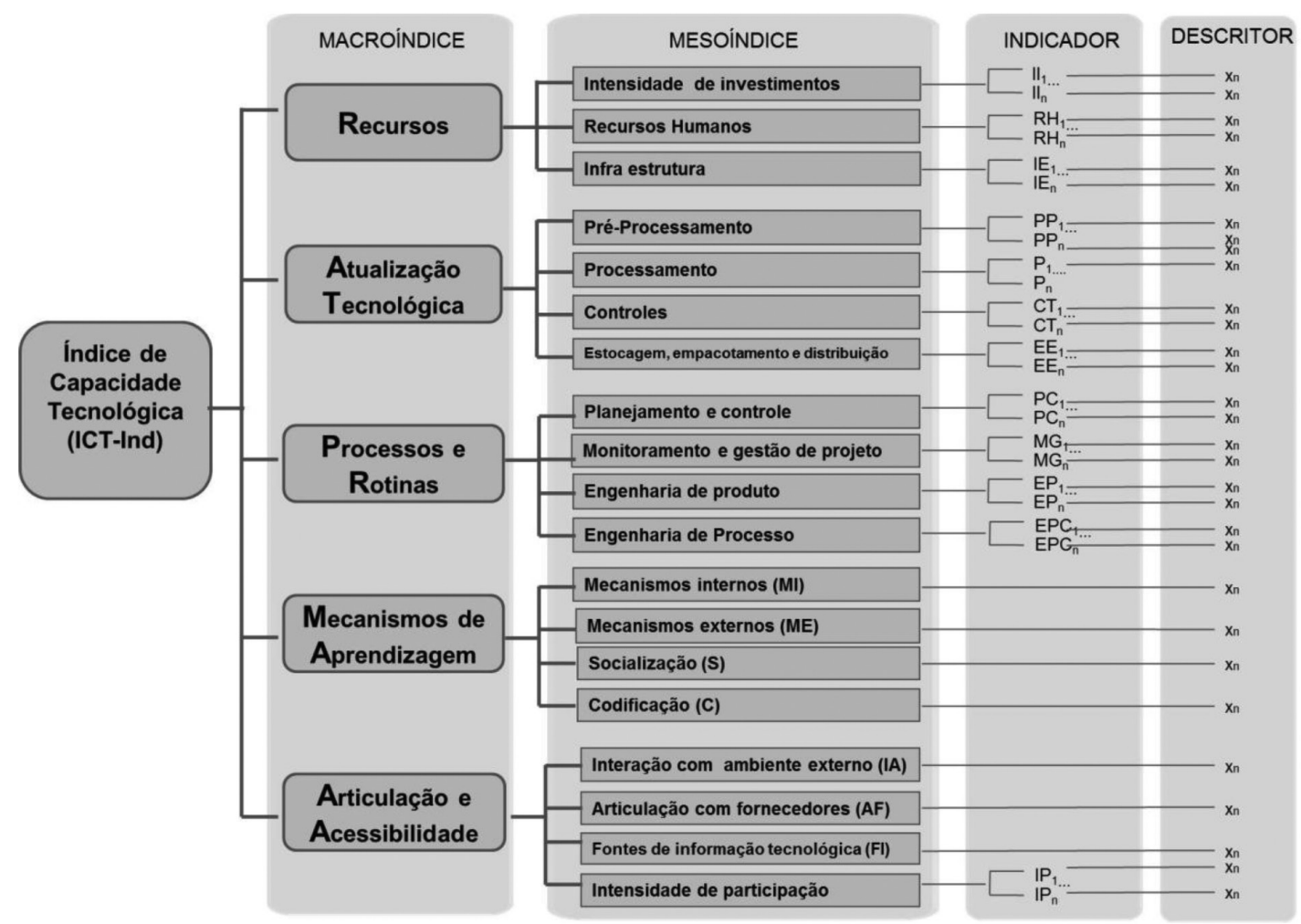

Figura 2. Arquitetura do Índice de Capacidade Tecnológica (ICT) proposta. Fonte: elaborado pelos autores.

segmento (trigo-grão, moagem e massas) seria muito extensa para ser apresentada neste artigo. Nesse sentido, o Anexo A apresenta a arquitetura completa do ICT para o segmento de massas para compreensão da proposta de índice. 0 conjunto de índices pode ser acessado pelo link http://www.gepai.dep.ufscar. br/artigos/Arquitetura_ICT_anexo_site.docx.

Os indicadores incluem variáveis quantitativas contínuas (p.ex., percentual de gastos em atividades de P\&D interna); quantitativas discretas de soma de eventos (p. ex., somatório da presença na empresa das seguintes atividades relacionadas a ações de melhoria de processo: programa de manutenção preventiva; banco de dados, análise de informações e procedimentos de correção; análise de problemas SAC e ações corretivas; treinamento continuado de recursos humanos; programa formal de melhoria contínua etc.); qualitativas binárias SIM ou NÃO (p. ex., existência de função ou departamento específico para desenvolvimento de atividades de PD\&I); qualitativas ordinais, ordenadas segundo nível de complexidade tecnológica ascendente (p. ex., indicador Gestão de qualidade expresso pelas categorias: N1 - Não possui prática formalizada em termos de gestão de qualidade; N2 - Controle estatístico de processo ou boas práticas de fabricação; N3 - Análise de Perigos e
Pontos críticos de Controle ou ISO 9000 ou ISO 14000; e N4 - 150 22000).

Este trabalho reconhece que, além dos elementos aqui considerados, fatores externos ao ambiente da firma influenciam a acumulação de capacidades tecnológicas (LALL, 1992; BELL; PAVITT, 1995; FIGUEIRED0, 2002) como, por exemplo, políticas governamentais, condições do mercado, alterações no comportamento do consumidor, dentre outros. Adicionalmente, a acumulação de capacidades também pode ser influenciada por outros fatores internos, como liderança e valores da empresa (LEONARD-BARTON, 1998; FIGUEIREDO, 2002). Embora importantes, esses elementos não serão considerados no modelo proposto.

Como comentado anteriormente, dadas as especificidades dos segmentos, foi elaborado um conjunto de pesos para cada segmento separadamente, com aplicação do procedimento de priorização e observação da coerência do método AHP. A Tabela 2 apresenta o conjunto de pesos obtido para os macroíndices nos diferentes segmentos. A observação das diferenças obtidas permite ratificar o aspecto de especificidade por tipo de atividade econômica. De maneira geral, o macroíndice Recursos (intensidade de investimento, recursos humanos e 
infraestrutura) foi considerado como componente de maior aporte ao estímulo das capacidades tecnológicas da empresa ao traduzir a lógica dos esforços financeiros, a infraestrutura existente e o grau de importância dado à qualificação e à capacitação do elemento essencial ao processo produtivo, os recursos humanos. Para alguns segmentos, o perfil das plantas e dos equipamentos utilizados tem pouca variação (espelhado pelo macroíndice Atualização tecnológica), o que acaba por atribuir ao macroíndice Processos e rotinas importância na diferenciação do perfil das empresas, em especial nas indústrias de produtos cliente-orientados e pluralidade de linhas de produtos, caso da moagem. Nos sistemas agrícolas, dado a aplicabilidade de tecnologias geradas fora da unidade, a observação da atualização tecnológica é um componente de grande importância na aferição da capacidade tecnológica da unidade.

\subsection{Aplicação do ICT ao complexo agroindustrial tritícola}

Para avaliar a aplicabilidade do índice, foram coletadas informações de 20 propriedades rurais: 13 propriedades do município de Palmeira das Missões, RS (região A), e 7 unidades do município de Arapongas, PR (região B). A área total das propriedades entrevistadas variou de 9,7 a 1.350,0 hectares. Já a aplicação do ICT nos segmentos industriais foi realizada em 5 moinhos, designados por A-MO, B-MO, C-MO, D-MO e E-MO, e 3 pastifícios A-MA, B-MA e C-MA.
A Tabela 3 sintetiza as principais características das empresas entrevistadas.

Na Tabela 4 apresentam-se os valores obtidos dos ICTs e dos macroíndices calculados. Como se pode observar, o ICT do conjunto de unidades agrícolas variou de 0,21 a 0,66 , com média de 0,44. Os macroíndices Recursos (RE) e Processos e rotinas (PR) apresentaram as menores médias e os maiores coeficientes de variação, 52,7\% e $46,4 \%$, respectivamente. Isto sugere debilidade desses componentes em relação aos demais e uma alta heterogeneidade de situações dentro do grupo, podendo ser esses componentes considerados como os principais diferenciadores entre os produtores em termos de CT. A sistematização de médias por tamanho de propriedade demonstra aumento dos valores do ICT com aumento do tamanho com correlação moderada positiva $(0,65)$. Tal comportamento sugere relação positiva entre nível de CT e escala produtiva. De forma semelhante, o agrupamento dos valores obtidos por região demonstra um melhor desempenho em termos de $\mathrm{CT}$ da região $\mathrm{A}$ em relação à região B. A construção desse tipo de análise demonstra 0 potencial do índice na identificação de lacunas e de diferenciações baseadas em critérios de tamanho e localização geográfica, por exemplo, podendo ser o mesmo usado em investigações de comportamento e de análise de fatores condicionantes.

0 ICT dos moinhos variou de 0,26 (empresa A-M0) a 0,74 (empresa E-MO). 0 macroíndice Atualização tecnológica (AT) obteve a menor amplitude de variação e o menor coeficiente de variação (19,3\%),

Tabela 2. Grau de importância de macroíndices (conjunto de pesos).

\begin{tabular}{lccc}
\multicolumn{1}{c}{ Macroíndices e mesoíndices } & Agrícola (\%) & Moagem (\%) & Massa (\%) \\
\hline RECURSO (RE) & 33,7 & 35,2 & 43,7 \\
ATUALIZAÇÃO TECNOLÓGICA (AT) & 37,2 & 17,0 & 17,1 \\
PROCESSOS E ROTINAS (PR) & 13,0 & 28,9 & 21,9 \\
MECANISMOS DE APRENDIZAGEM (MA) & 9,3 & 13,3 & 12,8 \\
ARTICULAÇÃO E ACESSIBILIDADE (AA) & 6,8 & 5,6 & 4,4 \\
\hline
\end{tabular}

Fonte: dados da pesquisa.

Tabela 3. Descrição das empresas entrevistadas para aplicação do ICT.

\begin{tabular}{ccccc}
\hline Empresa & Ano de fundação & Número de empregados & Receita operacional & Número de produtos \\
\hline A-MO & 1986 & MOINHOS & \\
B-MO & 1994 & 25 & Pequena empresa & 11 \\
C-MO & 1964 & 64 & Média empresa & 35 \\
D-MO & 1954 & 450 & Média empresa & 13 \\
E-MO & 1993 & 200 & Gédia empresa & 58 \\
\hline & 120 & & 220 \\
A-MA & 1964 & PASTIFíclOS éspresa & 54 \\
B-MA & 1911 & 450 & Média empresa empresa & 100 \\
\hline
\end{tabular}

Fonte: dados da pesquisa. 
Tabela 4. Valores de ICT e de macroíndices das unidades agrícolas, moinhos e pastifícios.

\begin{tabular}{|c|c|c|c|c|c|c|}
\hline \multirow{2}{*}{ Itens } & \multirow{2}{*}{ ICT } & \multicolumn{5}{|c|}{ Macroíndices } \\
\hline & & RE & AT & PR & MA & AA \\
\hline \multicolumn{7}{|c|}{ TRIGO-GRÃO } \\
\hline$\% 0<1 \leq 0,25$ & 5,0 & 25,0 & 0,0 & 15,0 & 0,0 & 0,0 \\
\hline$\% 0,25<1 \leq 0,5$ & 70,0 & 50,0 & 45,0 & 75,0 & 55,0 & 55,0 \\
\hline$\% 0,5<1 \leq 0,75$ & 25,0 & 25,0 & 55,0 & 10,0 & 30,0 & 40,0 \\
\hline$\% 0,75<1 \leq 1,0$ & 0,0 & 0,0 & 0,0 & 0,0 & 15,0 & 5,0 \\
\hline Pequena propriedade* & 0,37 & 0,32 & 0,42 & 0,21 & 0,53 & 0,39 \\
\hline Média propriedade* & 0,45 & 0,37 & 0,50 & 0,38 & 0,61 & 0,47 \\
\hline Grande propriedade* & 0,53 & 0,46 & 0,58 & 0,44 & 0,69 & 0,59 \\
\hline Região A & 0,47 & 0,42 & 0,52 & 0,35 & 0,61 & 0,51 \\
\hline Região B & 0,36 & 0,29 & 0,41 & 0,24 & 0,57 & 0,40 \\
\hline Média & 0,44 & 0,38 & 0,49 & 0,31 & 0,60 & 0,47 \\
\hline \multicolumn{7}{|c|}{ MOAGEM } \\
\hline A-MO & 0,26 & 0,17 & 0,39 & 0,22 & 0,39 & 0,33 \\
\hline B-MO & 0,52 & 0,52 & 0,59 & 0,48 & 0,60 & 0,30 \\
\hline C-MO & 0,42 & 0,31 & 0,45 & 0,48 & 0,54 & 0,48 \\
\hline D-MO & 0,68 & 0,53 & 0,61 & 0,88 & 0,84 & 0,48 \\
\hline E-MO & 0,74 & 0,79 & 0,61 & 0,61 & 1,00 & 0,77 \\
\hline Média & 0,52 & 0,46 & 0,53 & 0,53 & 0,67 & 0,47 \\
\hline \multicolumn{7}{|c|}{ MASSAS } \\
\hline A-MA & 0,57 & 0,52 & 0,93 & 0,53 & 0,44 & 0,39 \\
\hline B-MA & 0,39 & 0,39 & 0,70 & 0,27 & 0,29 & 0,19 \\
\hline C-MA & 0,76 & 0,62 & 0,93 & 0,86 & 0,81 & 0,77 \\
\hline Média & 0,45 & 0,48 & 0,52 & 0,35 & 0,44 & 0,46 \\
\hline
\end{tabular}

Fonte: dados da pesquisa. Siglas: Índice de Capacidade Tecnológica (1CT), macroíndice Recursos (RE), macroíndice Atualização tecnológica (AT), macroíndice Processos e rotinas (PR), macroíndice Mecanismos de aprendizagem (MA) e macroíndice Articulação e acessibilidade (AA). *Valores médios por tamanho de propriedade segundo a classificação pequena ( 1 a 4 módulos fiscais), média (4 a 15 módulos fiscais) e grande (mais de 15 módulos fiscais), de conformidade com art. $4^{\circ}$ da Lei n. $8.629 / 93$ (BRASIL, 1993).

o que pode indicar um grau de homogeneidade na incorporação de tecnologias de manufatura. Por outro lado, aspectos relacionados aos componentes Recursos (RE) e Processos e rotinas (PR) apresentaram as maiores amplitudes e os maiores coeficientes de variação, indicando comportamentos diferenciados nesses componentes. Já nos pastifícios, o ICT variou de 0,39 (B-MA) a 0,76 (C-MA). A empresa C-MA, com registro de maior valor de $\mathrm{ICT}$, obteve o maior valor em 4 dos 5 macroíndices, e a empresa B-MA apresentou os menores valores em 4 macroíndices. 0 macroíndice Articulação e acessibilidade (AA) apresentou o menor valor médio $(0,45)$ e a maior amplitude entre os valores mínimo e máximo. De forma semelhante ao grupo de moinhos, o macroíndice Atualização tecnológica (AT) obteve a menor amplitude de variação: de 0,70 a 0,93. Por outro lado, observaram-se importantes diferenças nos valores obtidos no macroíndice Processos e rotinas (PR).

A Figura 3 apresenta a análise de importância $x$ desempenho dos macroíndices para os casos estudados. Várias análises podem ser feitas a partir dessa figura. No caso dos moinhos, por exemplo, ações urgentes devem ser conduzidas pelos moinhos A-MO em aspectos vinculados aos macroíndices Recursos (RE) e Processos e rotinas (PR). Já o moinho C-MO também deve priorizar aspectos vinculados a Recursos (RE). 0 posicionamento do moinho E-MO, empresa com maior valor de ICT, encontra-se em equilíbrio na maioria dos elementos da CT (posicionamento na zona adequada ou em zonas limítrofes), havendo dois macroíndices, Mecanismos de aprendizagem (MA) e Articulação e acessibilidade (AA), na zona de excesso. No entanto, isto não necessariamente representa precisão de ações imediatas por parte da empresa, mas indica que ela deve avaliar a relação benefício/custo desse aspecto mais detalhadamente.

As evidências sugerem que as empresas que obtiveram maiores valores de ICT apresentam equilíbrio entre os diferentes componentes considerados. Relações positivas de correlação entre o valor do ICT obtido pelas empresas e o número de inovações tecnológicas implementadas relatadas pelas empresas foram observadas.

No intuito de exemplificar o potencial de exploração gerencial que pode ser conduzido a partir da aplicação do ICT, a Figura 4 apresenta detalhamento da posição dos valores obtidos pela empresa de menor valor ICT (B-MA), comparada com a média do grupo. Com base na Figura 4 é possivel identificar focos de melhoria para essa unidade que permitiriam expandir seu potencial tecnológico. De 
maneira geral, a empresa B-MA apresenta valores menores ou iguais à média do grupo em quase todos os macro e mesoíndices. Como, por exemplo, em relação ao macroíndice Recursos (RE), o grau de intensidade de investimento encontra-se bem abaixo dos valores das outras empresas $(0,5 \%$ da receita líquida de venda, sendo 5,0\% o maior percentual observado) e a empresa não possui a função de PD\&l formalizada.

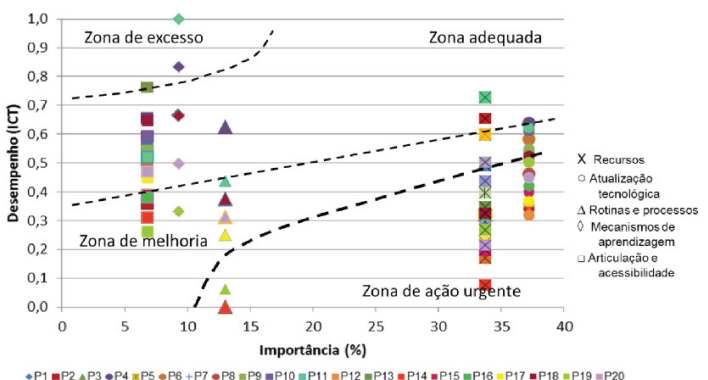

(a)

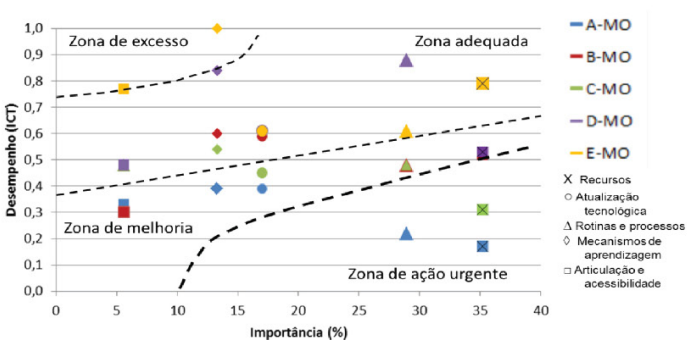

(b)

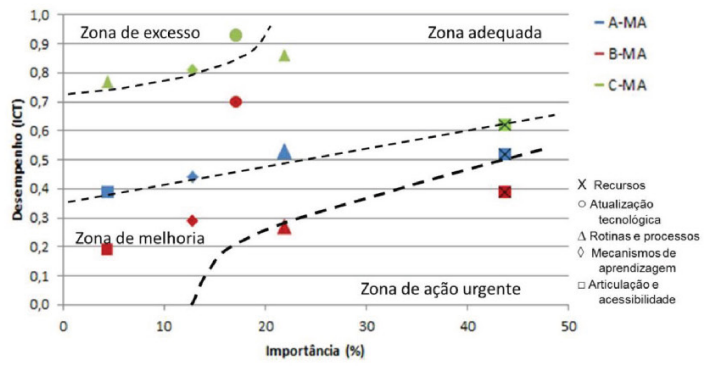

(c)

Figura 3. Análise importância x desempenho (ICT) das unidades agrícolas (a), moinhos (b) e pastifícios (c) entrevistados. Fonte: dados da pesquisa.

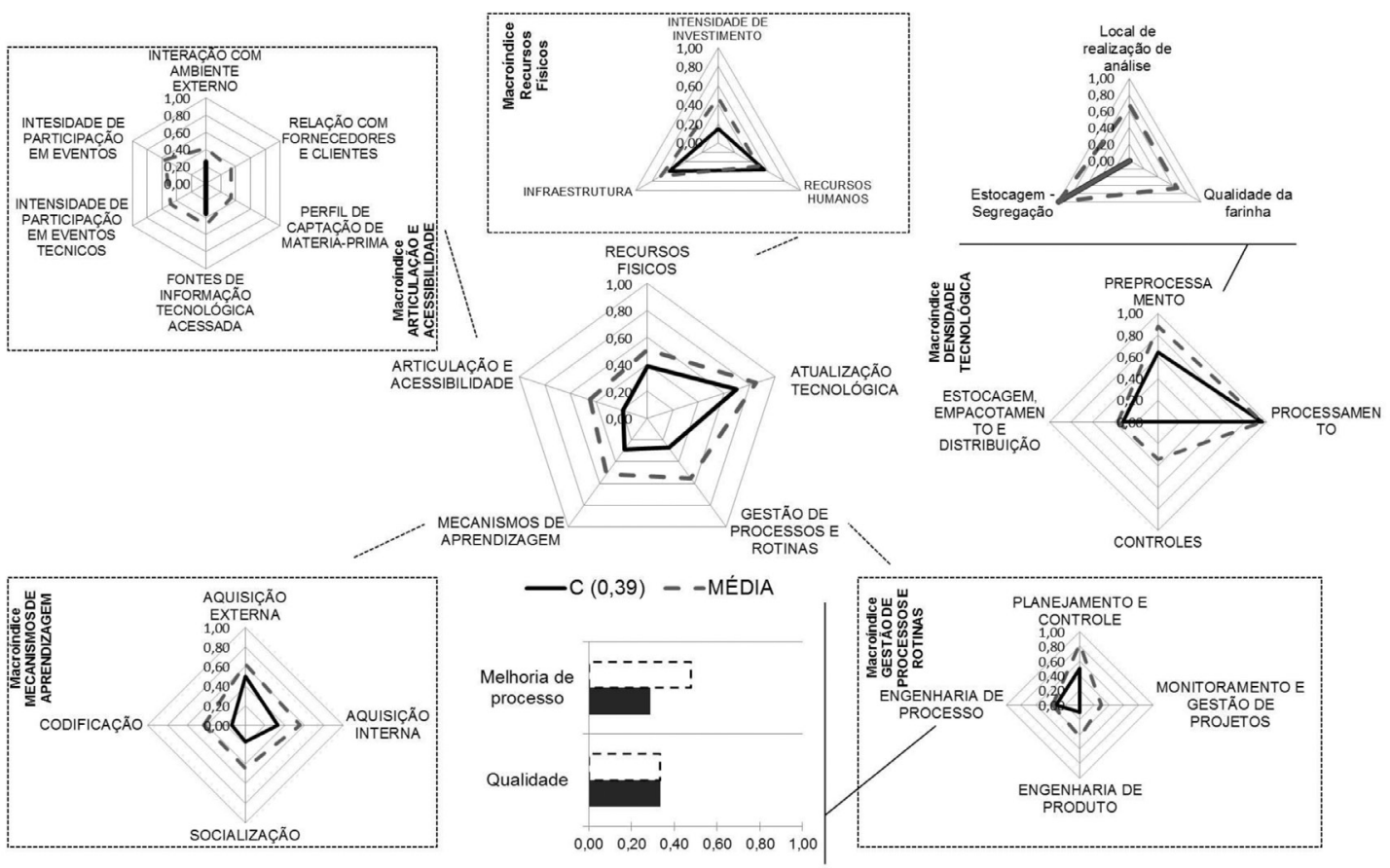

Figura 4. Posicionamento de valores de macro e mesoíndices da empresa de menor valor ICT e valor médio do grupo, segmento massas. 
Em termos do macroíndice Processos e rotinas (PR), a empresa não desenvolve ações de planejamento estratégico, monitoramento tecnológico, estudos de viabilidade de projetos e metodologia formal de desenvolvimento de produto.

Desde que disponha de uma amostra significativa, o ICT também permite avaliar a dinâmica tecnológica de um dado setor. Nos segmentos estudados é notória a incorporação de desenvolvimento tecnológico procedente de outros setores industriais, como da indústria de bens de capital e da indústria química, especialmente no caso de inovações de processo. Grande parte das mudanças tecnológicas observadas diz respeito ao aumento de velocidade de processamento, à integração de etapas para estabelecimento de linhas contínuas, aos equipamentos que permitam flexibilidade e multifuncionalidade, para ampliação do mix de produto ofertado, às automatizações para redução de uso de mão de obra e para redução de tempos de setup. No caso de insumos, observam-se alterações no intuito de ampliação de conservação do alimento (aditivos, conservantes e embalagem), enriquecimento do alimento em termos de nutrição e saúde e encurtamento de ciclo de produção. Mais do que produtos novos para o mercado, nas empresas entrevistadas encontrou-se a expansão de oferta de novas versões do produto-base ou a extensão para linhas de produtos com maior valor agregado.

Os valores e os coeficientes de variação obtidos no macroíndice Atualização tecnológica (AT) sugerem certa uniformidade na incorporação de tecnologias operativas entre as empresas. Nesse caso pode-se pensar que o nível de barreiras tecnológicas é baixo ou o acesso às alternativas tecnológicas é uniforme. Nesse quadro, os processos e rotinas vinculados ao conteúdo tecnológico, gestão e organização interelos e a interrelação com o meio tornam-se aspectos importantes na acumulação de capacidade tecnológica diferenciadora.

\section{Conclusões}

Este trabalho avança na discussão do conceito de CT, apresenta uma revisão das estruturas de mensuração da CT direcionadas a firmas e propõe um modelo de índice para mensuração da CT. 0 índice de CT é visto como uma construção de segunda ordem que contempla multidimensões (operacional, organizacional e relacional). Diferente das demais estruturas analíticas encontradas na literatura, o ICT proposto é calculado a partir de um conjunto de indicadores gerais de CT e de um conjunto de fatores específicos às empresas do setor analisado. Outros aspectos que diferenciam o modelo proposto dos demais observados são: (a) em relação à maioria das estruturas analíticas de indicadores isolados existentes para realização de análises comparativas descritivas, oferta uma estrutura de índice (indicadores agregados), complementando com estruturas de análise gerencial; e (b) as variáveis adotadas são observáveis diretamente (por exemplo, percentual médio anual de permanência de pessoal na empresa, presença ou ausência de função ou departamento para desenvolvimento de atividades de PD\&l, percentual de funcionários com nível de instrução técnico de $2^{\circ}$ grau, graduação e pós-graduação etc.), evitando escalas ou categorias de opinião (por exemplo, atribuição de pontuação de 1 a 5 , baixa, média, alta, ruim, boa etc.) empregadas em algumas das estruturas existentes na literatura.

0 modelo foi capaz de captar nitidamente as diferenças de CT entre as empresas inqueridas. Além disso, os resultados permitiram realizar análises que permitem às empresas identificar necessidades de melhoria nas suas CT. A geração dessas informações, com a construção de gráficos de saída, pode ser considerada um dos pontos fortes do modelo proposto. Elas permitem à empresa se posicionar frente a um quadro ideal e identificar os possíveis pontos que permitiriam melhorar as suas habilidades.

Os baixos valores obtidos nos índices ICT, inclusive de empresas com maior tempo de mercado, estimulam a discussão sobre o grau de importância da tecnologia como fator direcionador da competitividade do setor agroindustrial brasileiro. Assim, fatores como estrutura de mercado, perfil de oferta e preço de matéria-prima, perfil de demanda e vantagens de localização poderiam ser mais importantes do que a tecnologia para explicar a competitividade - ou sua ausência - das agroindústrias brasileiras?

0 modelo proposto apresenta limitações tais como (a) a amostra relativamente pequena pode comprometer a sua validação; (b) embora avance no intuito de estabelecer indicadores mais concretos, evitando julgamentos de escala na sua composição, os indicadores limitam-se, na sua grande maioria, ao uso de escalas nominais ou ordinais; (c) a não consideração de fatores externos ao ambiente da firma limita a possibilidade de comparações regionais; (d) a escolha da tecnologia mais adequada depende da estratégia da empresa; e (e) a natureza intrinsecamente limitada de um índice no provimento da informação necessária aos usuários pode levar a conclusões simplistas sobre o fenômeno observado.

0 refinamento dos elementos e das variáveis, o aperfeiçoamento do sistema de ponderação, a expansão do número de aplicações do índice nos segmentos estudados para obter uma maior robustez de informações dos segmentos e da aplicabilidade do modelo, a elaboração de modelos para outros segmentos do complexo agroindustrial, a proposição de 
modelos de análise da capacidade tecnológica setorial que englobem, além das características inerentes à análise das aptidões das empresas individualmente, aspectos que qualifiquem o perfil setorial, a aplicação de outros modelos matemáticos de agregação, como o método fuzzy, e a programação por metas são sugestões de trabalhos futuros.

Dadas suas limitações amostrais, os resultados obtidos em termos de valores e comportamento dos segmentos não pode ser generalizado para o conjunto dos segmentos analisados. Porém o aprofundamento do entendimento do conceito de CT, suas formas de mensuração e a construção de ferramental que auxilie no diagnóstico e monitoramento do fenômeno no âmbito da empresa podem ser considerados como contribuições do presente trabalho.

\section{Referências}

ASSOCIAÇÃO BRASILEIRA DAS INDÚSTRIAS DA ALIMENTAÇÃO - ABIA. Faturamento. São Paulo: ABIA, 2012. Disponível em: <http://abia.org.br/vst/ faturamento.pdf>. Acesso em: 25 out. 2012.

ASSOCIAÇÃO BRASILEIRA DAS INDÚSTRIAS DE MASSAS ALIMENTÍCIAS E PÃO \& BOLO INDUSTRIALIZADOS - ABIMA. Exportação - Massas brasileiras. Disponivel em: <http://www.abima.com.br/ estMassasBrasileiras.asp>. Acesso em: 29 out. 2012.

ASSOCIAÇÃO BRASILEIRA DA INDÚSTRIA DO TRIGO - ABITRIGO. Moinhos em atividade no Brasil - 2010. São Paulo: ABITRIGO, 2011.

ADLER, P. S.; SHENBAR, A. Adopting your technological base: the organizational challenge. Sloan Management Review, v. 32, n. 1, p. 25-37, 1990.

ARIFFIN, N.; FIGUEIREDO, P. N. Internationalization of innovative capabilities: counter-evidence from the electronics industry in Malaysia and Brazil. In: DRUID SUMMER CONFERENCE, 2003, Copenhagen. Proceedings.... Copenhagen: DRUID, 2003. Disponivel em: <http://www.druid.dk/conferences/summer2003/papers/ ARIFFIN_FIGUEIREDO.pdf>. Acesso em: 23 nov. 2010.

AZZOPARDI, E.; NASH, R. A critical evaluation of importance-performance analysis. Tourism Management, p. 1-12, 2012. Article in press.

BATALHA, M. 0.; SILVA, A. L. Gerenciamento de sistemas agroindustriais: definições, especificações, especificidades e correntes metodológicas. In: BATALHA, M. 0. (Coord.). Gestão Agroindustrial. 3. ed. São Paulo: Atlas, 2007. p. 1-62.

BELL, M. Technical change in infant industries: a review of the empirical evidence. Brighton: SPRU, 1982. Mimeo.

BELL, M.; PAVITT, K. Technological accumulation and industrial growth: contrast between developed and developing country. Industrial and Corporate Change, v. 2, n. 2, p. 157210, 1993. http://dx.doi.org/10.1093/icc/2.1.157

BELL, M.; PAVITT, K. The development of technological capabilities. In: HAQUE, l. U. (Ed.). Trade, Technology and International Competitiveness. Washington: World Bank, 1995. p. 60-101.
BIGGS, T.; SHAH, M.; SRIVASTAVA, P. Technological capabilities and learning in african enterprises. Washington: World Bank, 1995. 235 p. (Technical Paper, n. 228).

BRASIL. Presidência da República. Casa Civil. Lei $n^{\circ}$ 8.629/93, de 25 de fevereiro de 1993. Dispõe sobre a regulamentação dos dispositivos constitucionais relativos à reforma agrária, previstos no Capítulo 111, Título VII, da Constituição Federal. Diário Oficial da República Federativa do Brasil, Brasília, DF, 26 fev. 1993. Seção 1, p. 2349.

CASTRO, E. C. Acumulação de competências tecnológicas e processos de aprendizagem: o caso da aciaria da Companhia Siderúrgica Nacional. 2002. 182 f. Dissertação (Mestrado em Administração)-Escola Brasileira de Administração Pública e Empresarial, Fundação Getulio Vargas, Rio de Janeiro, 2002.

CHRISTENSEN, C.; OVERDORF, M. Meeting the challenge of disruptive change. Harvard Business Review, v. 78, n. 2, p. 66-76, 2000.

CLARK, K. B.; FUJIMOTO, T. Product development performance. Boston: Harvard Business School Press, 1991. 409 p.

COOMBS, J. E.; BIERLY, P. E. Measuring technological capability and performance. $R \& D$ Management, v. 36, n. 4, p. 421-438, 2006. http://dx.doi.org/10.1111/j.14679310.2006.00444.x

DICHTER, D. et al. A guide to technology transfer for small and medium-sized enterprises. Newcastle: Gower Publishing, 1988. $156 \mathrm{p}$.

ENOS, J. L. The creation of technological capability in developing countries. Londres: Pinter Publishers, 1991. 224 p.

FlGUEIREDO, P. N. Acumulação tecnológica e inovação industrial - conceitos, mensuração e evidências no Brasil. São Paulo em Perspectiva, v. 19, n. 1, p. 54-69, jan./mar. 2005. http://dx.doi.org/10.1590/S0102-88392005000100005

FIGUEIREDO, P. N. Does technological learning pay off? Implications for inter-firm differences in operational performance improvement. Research Policy, v. 31, n. 1, p. 73-94, 2002. http://dx.doi.org/10.1016/S00487333(01)00106-8

FORMAN, E.; GASS, S. The analytic hierarchy process - An exposition. Operations Research, v. 49, n. 4, p. 469486, 2001. http://dx.doi.org/10.1287/opre.49.4.469.11231

FREUDENBERG, M. Compositeindicators of countryperformance: A critical assessment. Paris: OECD Publishing, 2003. 35 p. (OECD Science, Technology and Industry Working Papers). http://dx.doi.org/10.1787/405566708255

GARUTI, A. C.; SALOMON, V. A. P.; SPENCER G. I. A systemic rebuttal to the criticism of using the eigenvector for priority assessment in the analytic hierarchy process for decision making. Computación y Sistemas, v. 4, n. 2, p. 192-207, 2008.

GARVIN, D. A. Building a learning organization. Harvard Business Review, v. 71, n. 4, p. 78-91, jul./ago. 1993.

GOMES, L. F. A. M. Teoria da decisão. São Paulo: Pioneira Thomson Learning, 2007. $116 \mathrm{p}$.

GUAN, J.; MA, N. Innovative capability and export performance of chinese firms. Technovation, v. 23, n. 9, p. 737-747, 2003. http://dx.doi.org/10.1016/S01664972(02)00013-5

GUGliElMETTI, F.; MARINS, F.; SALOMON, V. A. P. Comparação teórica entre métodos de auxílio à tomada de decisão por múltiplos critérios. In: ENCONTRO NACIONAL 
DE ENGENHARIA DE PRODUÇÃO, 23., 2003, Ouro Preto. Anais... Ouro Preto: ABEPRO - UFOP, 2003. Disponível em: <http://www.abepro.org.br/biblioteca/ENEGEP2003_ TR0602_0237.pdf>. Acesso em: 03 nov. 2012.

HO, W. Integrated analytic hierarchy process and its applications - a literature review. European Journal of Operational Research, v. 186, n. 1, p. 211-228, 2008. http://dx.doi.org/10.1016/j.ejor.2007.01.004

INSTITUTO BRASILEIRO DE GEOGRAFIA E ESTATÍSTICA - IBGE. Pesquisa de inovação tecnológica 2005. Rio de Janeiro: IBGE, 2007. 156 p. Disponível em: <http://www.ibge. gov.br/home/estatistica/economia/industria/pintec/2005/ pintec2005.pdf>. Acesso em: 12 jun. 2008.

INSTITUTO BRASILEIRO DE GEOGRAFIA E ESTATÍSTICA - IBGE. Censo Agropecuário: Brasil, grandes regiões e unidades da federação. Rio de Janeiro: IBGE, 2009. 771 p.

INSTITUTO PARANAENSE DE DESENVOLVIMENTO ECONÔMICO E SOCIAL - IPARDES. Identificação de gargalos tecnológicos da agroindústria paranaense: subsídios para uma política pública. Curitiba: IPARDES, 2005. 126 p.

ISHIZAKA, A.; LABIB, A. Review of the main developments in the analytic hierarchy process. Expert systems with applications, v. 38, n. 11, p. 14336-14345, 2011.

JONKER, M.; ROMIJN, H.; SZIRMAl, A. Technological effort, technological capabilities and economic performance of the paper manufacturing sector in West. Technovation, v. 26, n. 1, p. 121-134, 2006. http://dx.doi.org/10.1016/j. technovation.2004.10.002

KATZ, J. M. Domestic technology generation in LDCs: A review of research findings. In: KATZ, J. M. Technology generation in Latin American manufacturing industries: theory and case-studies concerning its nature, magnitude and consequences. London: Macmillan, 1987. p. 13-56.

LABIB, A. W. A supplier selection model: a comparison of fuzzy logic and the analytic hierarchy process. International Journal of Production Research, v. 49, n. 21, p. 6287-6299, 2011. http://dx.doi.org/10.1080/00 207543.2010.531776

LALL, S. Technological capabilities and industrialization. World Development, v. 20, n. 2, p. 165-186, 1992. http://dx.doi.org/10.1016/0305-750X(92)90097-F

LALL, S. Technological learning in the third world: some implications of technology exports. In: STEWART, F.; JAMES, J. (Ed.). The economics of new technology in developing countries. London: Frances Pinter, 1982. p. 157-179.

LEBAS, M. J. Performance measurement and performance management. International Journal Production Economics, v. 41, n. 1-3, p. 23-35, 1995. http://dx.doi. org/10.1016/0925-5273(95)00081-X

LEE, S.-H. Using fuzzy AHP to develop intellectual capital evaluation model for assessing their performance contribution in a university. Expert systems with applications, v. 37, n. 7, p. 4941-4947, 2010. http:// dx.doi.org/10.1016/j.eswa.2009.12.020

LEONARD-BARTON, D. Nascentes do saber: criando e sustentando as fontes de inovação. Rio de Janeiro: Fundação Getúlio Vargas, 1998. 367 p.

LU, 1. Y.; CHEN, C.; WANG, C. Fuzzy multivariate analysis for evaluating firm technological innovation capability. International Journal Technology Management, v. 40, n. 1-3, p. 114-130, 2007. http://dx.doi.org/10.1504/ IJTM.2007.013530
MALAVSKI, O. S.; LIMA, E. P.; COSTA, S. E. G. Modelo para a mensuração do capital intelectual: uma abordagem fundamentada em recursos. Produção, v. 20, n. 3, p. 439-454, 2010. http://dx.doi.org/10.1590/S010365132010005000050

MALERBA, F. Learning by firms and incremental technical change. Economic Journal, v. 102, n. 413, p. 845859, 1992. http://dx.doi.org/10.2307/2234581

MARCOVITCH, J. A Questão da competitividade. In: VELlOSO, J. P. R. (Org.). Desenvolvimento, tecnologia e governabilidade. São Paulo: Nobel, 1994. p. 167-191.

MARTILLA, J. A.; JAMES, J. C. Importance-perfomance analysis. Journal of Marketing, v. 41, n. 1, p. 7779. 1977. http://dx.doi.org/10.2307/1250495

MIYAJl, M.; SOARES, C. F. Avaliação da capacitação tecnológica das micro e pequenas empresas de laticínios da região do circuito do queijo em Minas Gerais. In: SIMPÓSIO DE GESTÃO DA INOVAÇ̃̃O TECNOLÓGICA, 22., 2002, Salvador. Anais... Salvador: NPGCT/USP, 2002. 1 CD-ROOM.

NEVES, M. C. Capacidades e demandas tecnológicas de indústrias alimentícias da Baixada Cuiabana e o potencial de interação com as universidades matogrossenses. 2000. 117 f. Dissertação (Mestrado em Administração)-Universidade Federal do Rio Grande do Sul, Porto Alegre, 2000.

ORGANIZAÇÃO PARA A COOPERAÇÃO E DESENVOLVIMENTO ECONÓMICO - OCDE. Manual de Oslo: diretrizes para coleta e interpretação dos dados sobre inovação. 2. ed. OECD/EU/EUROSTAT, 2005. 184 p. Disponível em: $<$ http://www.finep.gov.br/imprensa/sala_imprensa/ manual_de_oslo.pdf>. Acesso em: 17 ago. 2007.

ORGANIZAČ̃̃ PARA A COOPERAÇÃO E DESENVOLVIMENTO ECONÓMICO - OCDE. OECD environmental indicators: development, measurement and use. Paris: OECD, 2003. 37 p. Disponivel em: <http://www.oecd.org/ dataoecd/7/47/24993546.pdf> Acesso em: 12 abr. 2008.

PACK, H. Productivity, technology and industrial development: a case study in textiles. New York: Oxford University Press, 1987. $193 \mathrm{p}$.

PANDA, H.; RAMANATHAN, K. Technological capability assessment of a firm in the electricity sector. Tecnovation, v. 16, n. 10 , p. 561-588, 1996. http://dx.doi.org/10.1016/ S0166-4972(97)82896-9

PAOLI, D.; MORAES, L. A. F. Apoio multicritério à decisão como subsídio à gestão ambiental: o caso da Aggreko Brasil. Gestão da Produção, v. 18, n. 2, p. 379-390, 2011. http://dx.doi.org/10.1590/S0104-530X2011000200012

ROSADO JÚNIOR, A. G.; LOBATO, J. F. P.; MÜLlER, C. Building consolidated performance indicators for an agribusiness company: a case study. Revista Brasileira de Zootecnia, v. 40, n. 2, p. 454-461, 2011.

SAATY, T. L. Método de Análise Hierárquica. São Paulo: Makron Books, 1991. 367 p.

SAATY, T. L. Theory and applications of the analytic network process: decision making with benefits, opportunities, costs, and risks. Pittsburgh: RWS Publications, 2005. 352 p.

SAATY, T. L.; VARGAS, L. G.; WHITAKER, R. Addressing with brevity criticism of the Analytic Hierarchy Process. International Journal of the Analytic Hierarchy Process, v. 1, n. 2, p. 121-134, 2009.

SALOMON, V. A. P. Contribuições para validação de tomada de decisão com múltiplos critérios. 2010. 68 f. Tese 
(Livre-Docência)-Universidade Estadual Paulista Júlio de Mesquita Filho, Guaratinguetá, 2010.

SERRA, N.; PLONSKI, G. A. Competitividade, capacitação e aprendizagem tecnológica na indústria de máquinas têxteis. Produção, v. 7, n. 1, p. 5-16, 1997. http://dx.doi. org/10.1590/S0103-65131997000100001

SEVERIANO FILHO, C. $O$ enfoque vetorial da produtividade em um sistema de avaliação para a manufatura avançada na indústria de alimentos. 1995. 287 f. Tese (Doutorado em Engenharia de Produção)-Universidade Federal de Santa Catarina, Florianópolis, 1995.

SLACK, N.; LEWIS, M. Estratégia de operações. 2. ed. Porto Alegre: Bookman, 2009. 528 p.

SLACK, N. The importance-performance matrix as a determinant of improvement priority. International Journal of Operations and Production Management, v. 14, n. 5, p. 5975, 1994. http://dx.doi.org/10.1108/01443579410056803

STALK, G.; EVANS, P.; SHULMAN, L. E. Competing on capabilities: the new rules of corporate strategy. Harvard Business Review, v. 70, n. 2, p. 57-69, 1992.

SU, S.; YU, J.; ZHANG, J. Measurements study on sustainability of China's mining cities. Expert systems with applications, v. 37, n. 8, p. 6028-6035, 2010. http:// dx.doi.org/10.1016/j.eswa.2010.02.140

TACLA, C. L.; FIGUEIREDO, P. N. Processos de aprendizagem e acumulação de competências tecnológicas: evidências de uma empresa de bens de capital no Brasil. Revista de Administração Contemporânea, v. 7, n. 3, p. 101126, jul./set. 2003. http://dx.doi.org/10.1590/S141565552003000300006

TREMBLAY, P. J. Technological capability and productivity growth: an industrialized industrializing country comparison. Montreal: Cirano, 1998. 32 p. (Scientific Series 98-07).
VAIDYA, O. S.; KUMAR, S. Analytic hierarchy process: an overview of applications. European Journal of Operational Research, v. 169, n. 1, p. 1-29, 2006. http:// dx.doi.org/10.1016/j.ejor.2004.04.028

VILAS BOAS, C. L. Modelo multicritérios de apoio à decisão aplicado ao uso múltiplo de reservatórios: estudo da Barragem do Ribeirão João Leite. 2006. 158 f. Dissertação (Mestrado em Gestão Econômica do Meio Ambiente)Universidade de Brasília, Brasília, 2006.

WALLENIUS, J. et al. Multiple criteria decision making, multiattribute utility theory: recent accomplishments and what lies ahead. Management Science, v. 54, n. 7, p. 1336-1349, 2008. http://dx.doi.org/10.1287/ mnsc. 1070.0838

YAM, R. C. M. et al. Technological innovation capabilities and firm performance. World Academy of Science, Engineering and Technology, n. 66, p. 1023-1031, 2010.

YAM, R. C. M. et al. An audit of technological innovation capabilities in chinese firms: some empirical findings in Beijing, China. Research Policy, v. 33, n. 8, p. 1123-1140, 2004. http://dx.doi.org/10.1016/j. respol.2004.05.004

ZAMBON, K. L. et al. Análise de decisão multicritério na localização de usinas termoelétricas utilizando SIG. Pesquisa Operacional, v. 25, n. 2, p. 183-199, maio/ ago. 2005.

\section{Agradecimentos}

Os autores agradecem aos revisores os úteis comentários e sugestões.

\section{Technological capability: an index model and application to wheat agro-industrial complex firms}

\section{Abstract}

Technological capability is a determining factor in the efficiency and effectiveness of the production processes of companies and directly influences their degree of innovativeness. Quantifying this capability can help organizations to evaluate their capacities to absorb, use, adapt, generate, develop, transfer and disseminate technologies. This article develops a model for measurement of technological capability and applies this model to wheat agro-industrial companies (wheat farms, mills and pasta manufacturers). The index model is based on five macro index components: (i) resources, (ii) technological upgrading, (iii) processes and routines, (iv) learning mechanisms, and (v) coordination and accessibility. The index is a weighted sum of the values of quantitative and qualitative variables and uses the AHP multicriteria analysis method to compose the weighting. Importance-performance matrix analysis and spider charts are used to present and examine the data. To evaluate the index, interviews were conducted with personnel at 20 farms, 5 mills and 3 pasta manufacturing plants.

\section{Keywords}

Agribusiness. Technological management. Capability index. 


\begin{tabular}{|c|c|c|c|c|c|c|c|c|c|c|c|c|c|c|c|c|c|}
\hline \multirow{3}{*}{ 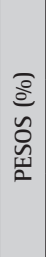 } & \multicolumn{14}{|c|}{$\stackrel{\text { :े }}{\dot{q}}$} & \\
\hline & \multicolumn{8}{|c|}{$\stackrel{\circ}{\dot{y}}$} & \multicolumn{3}{|c|}{$\stackrel{\circ}{\stackrel{\gamma}{\gamma}}$} & \multicolumn{3}{|c|}{ ڤ̊ } & \multicolumn{3}{|c|}{ iे } \\
\hline & 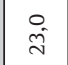 & $\stackrel{\circ}{\circ}$ & 8 & $\stackrel{i}{m}$ & : & $\stackrel{\circ}{\dot{N}}$ & $\stackrel{\circ}{i}$ & $\stackrel{\circ}{\stackrel{0}{\therefore}}$ & $\stackrel{0}{ \pm}$ & $\begin{array}{ll}0 & 0 \\
0 & 0 \\
0\end{array}$ & 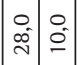 & $\begin{array}{l}\dot{\sigma} \\
\dot{\sigma}\end{array}$ & ڤ્ & 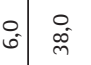 & $\infty^{\circ}$ & $\stackrel{\circ}{\stackrel{\circ}{s}}$ & : \\
\hline & 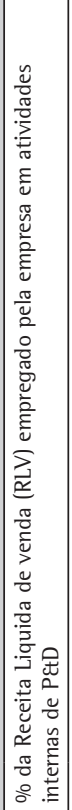 & 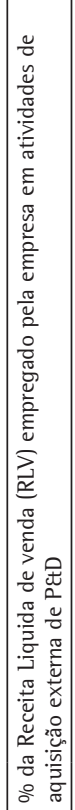 & 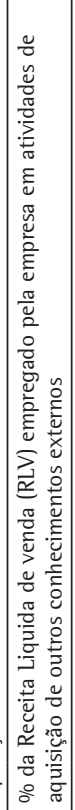 & 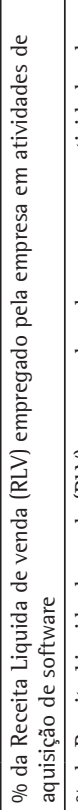 & 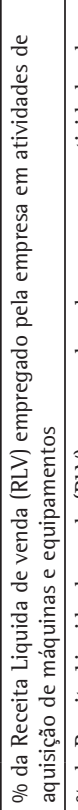 & 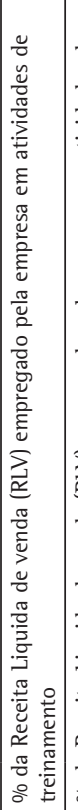 & 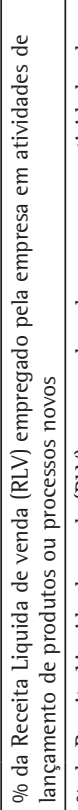 & 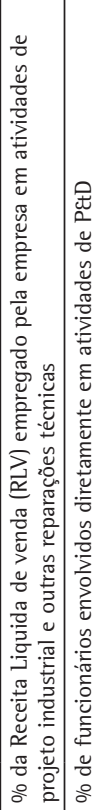 & 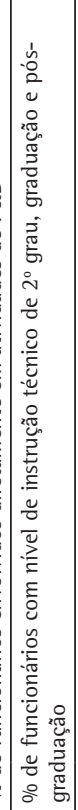 & 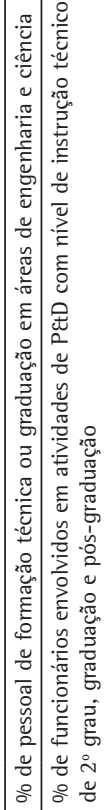 & 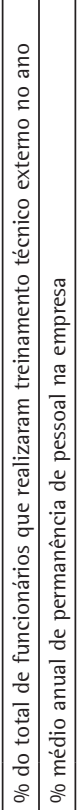 & | & 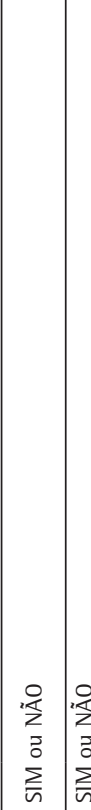 & 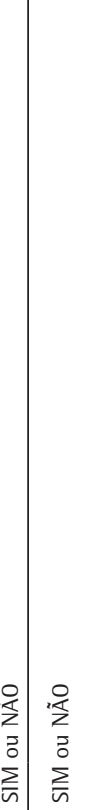 & 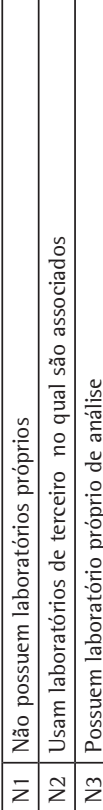 & 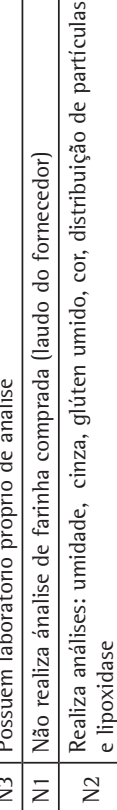 & 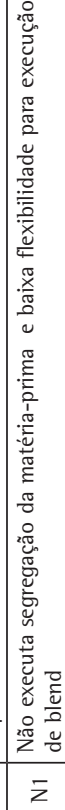 \\
\hline 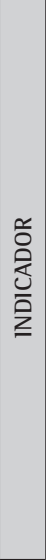 & 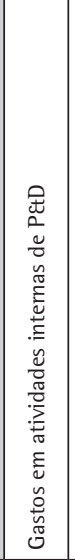 & 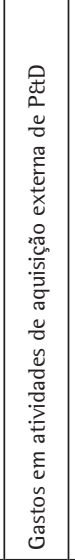 & 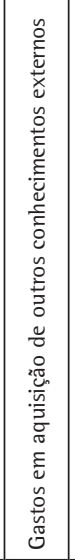 & 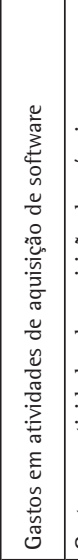 & 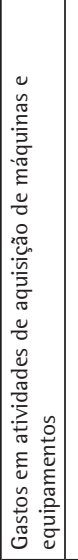 & 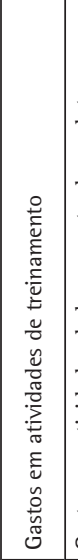 & 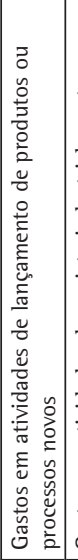 & 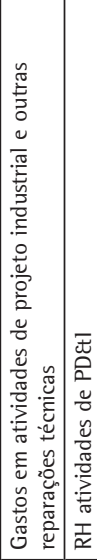 & 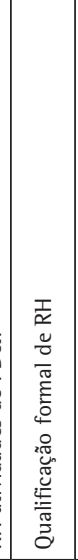 & 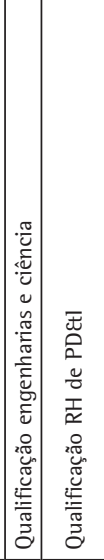 & 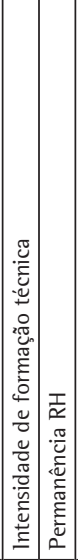 & 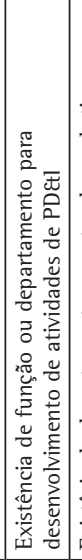 & 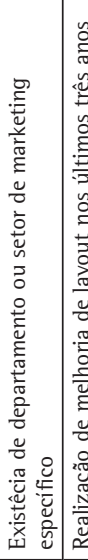 & 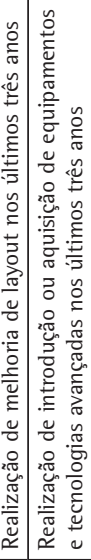 & 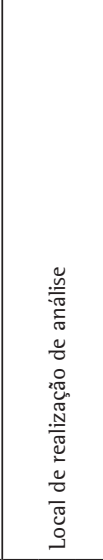 & 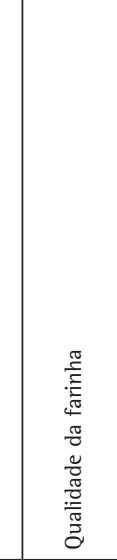 & 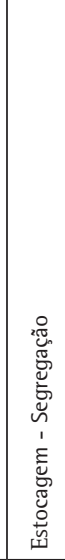 \\
\hline & & & & 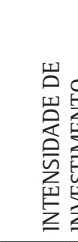 & 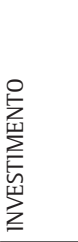 & & & & & 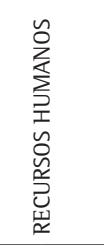 & & & 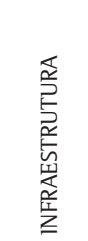 & & & 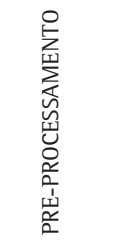 & \\
\hline 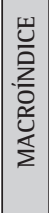 & & & & & & & & 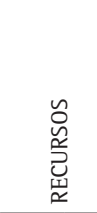 & & & & & & & & 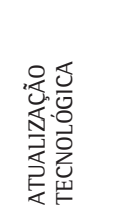 & \\
\hline
\end{tabular}


De Mori, C. et al.

Capacidade tecnológica: proposição...complexo agroindustrial do trigo. Production, v. 24, n. 4, p. 787-808, oct./dec. 2014

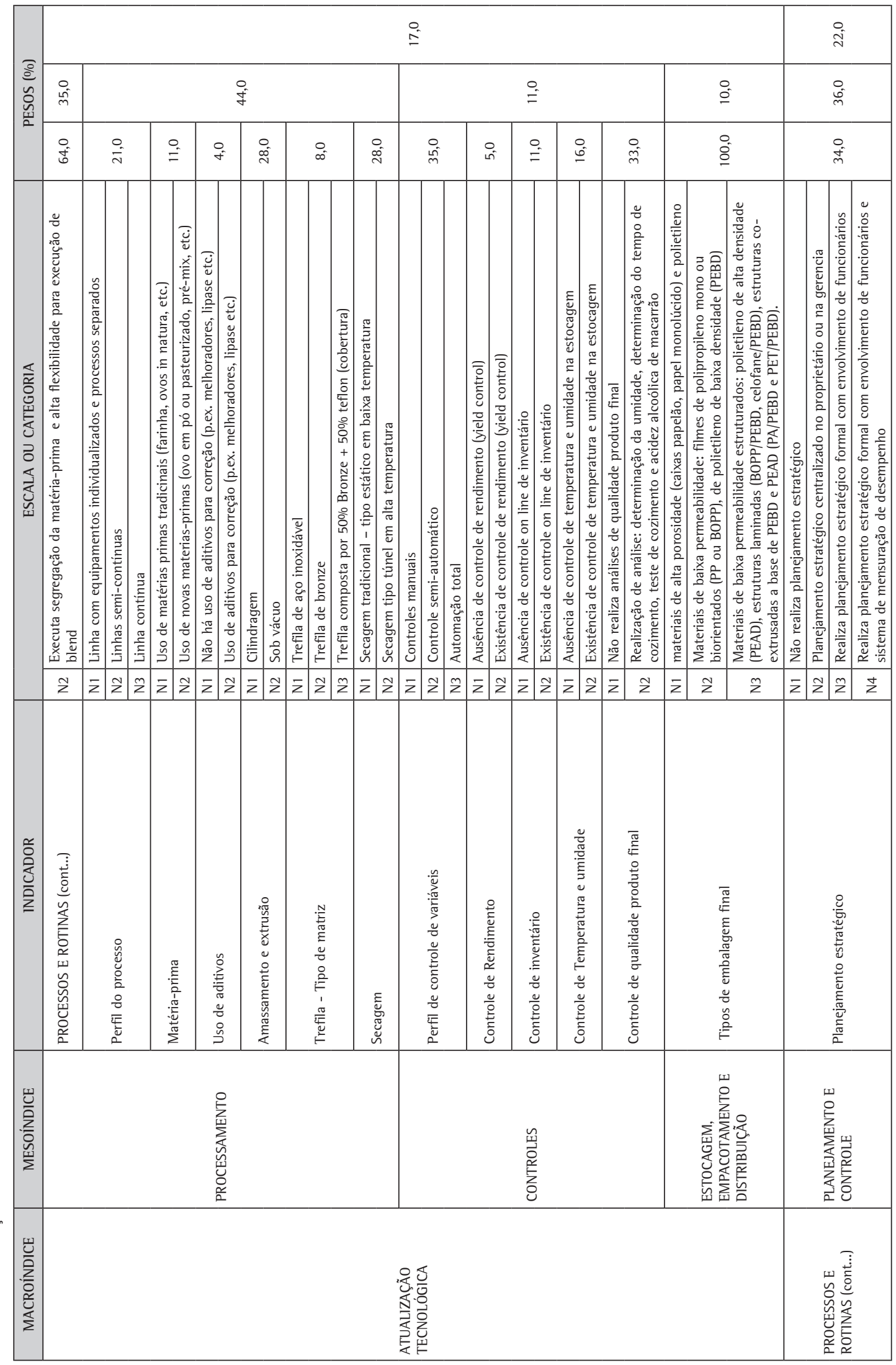




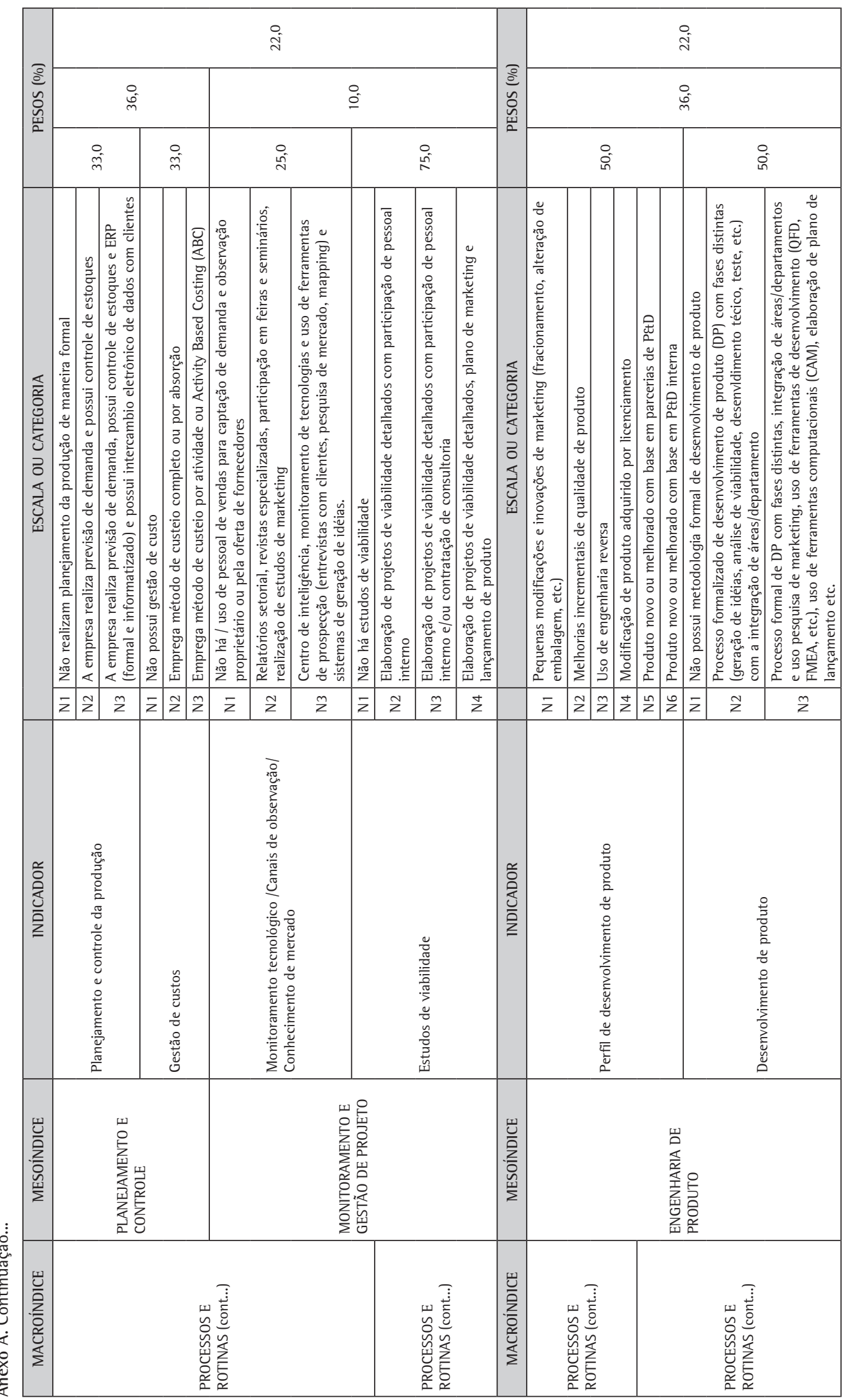




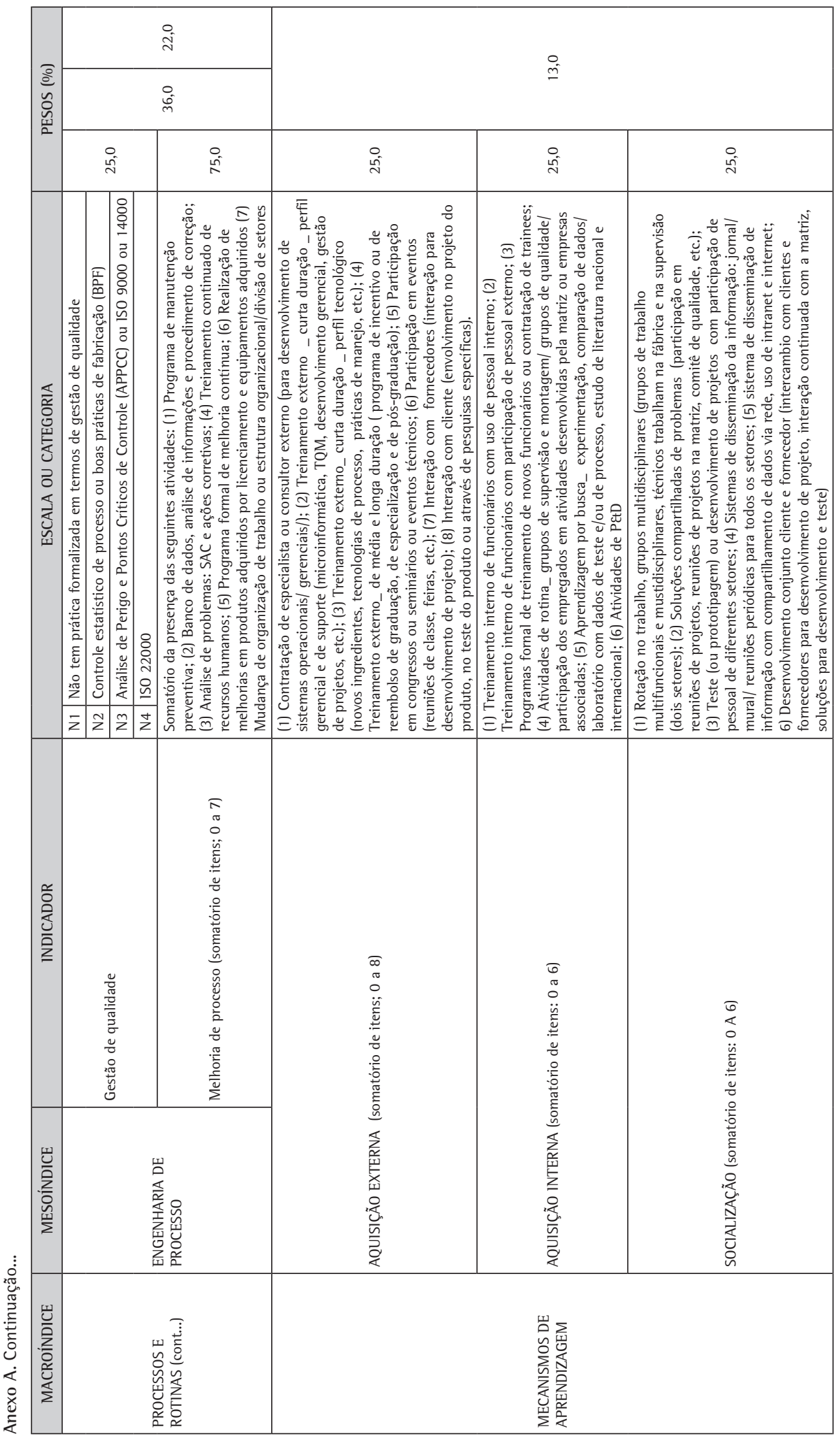




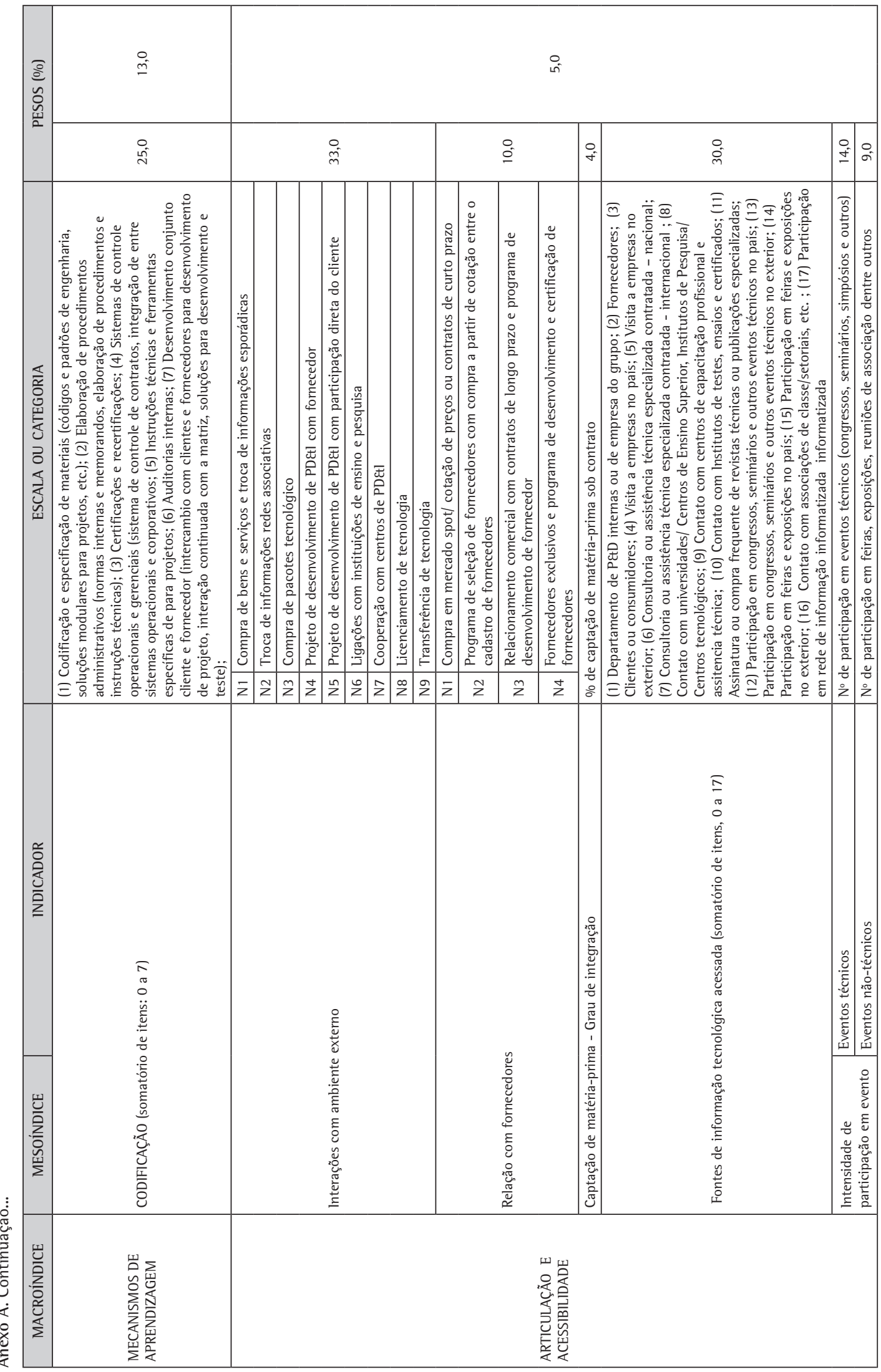

